\title{
Altered gene expression changes in Arabidopsis leaf tissues and protoplasts in response to Plum pox virus infection Mohan Babu1,3, Jonathan S Griffiths ${ }^{1,2,4}$, Tyng-Shyan Huang ${ }^{1,2}$ and Aiming Wang*1,2
}

\begin{abstract}
Address: ${ }^{1}$ Southern Crop Protection and Food Research Centre, Agriculture and Agri-Food Canada, 1391 Sandford St., London, Ontario, N5V 4T3, Canada, ${ }^{2}$ Department of Biology, The University of Western Ontario, Biological \& Geological Building, 1151 Richmond St., London, Ontario, N6A 5B7, Canada, ${ }^{3}$ Department of Molecular Genetics, The University of Toronto, M5S 1A8, Canada and ${ }^{4}$ Department of Botany, The University of British Columbia, Vancouver, V6T 1Z4, Canada
\end{abstract}

Email: Mohan Babu - mohanbabu_r@yahoo.com; Jonathan S Griffiths - jayphive@gmail.com; Tyng-Shyan Huang - thuang45@uwo.ca; Aiming Wang* - wanga@agr.gc.ca

* Corresponding author

Published: 9 July 2008

BMC Genomics 2008, 9:325 doi:10.1/86/147|-2164-9-325
Received: 24 December 2007

Accepted: 9 July 2008

This article is available from: http://www.biomedcentral.com//47I-2/64/9/325

(C) 2008 Babu et al; licensee BioMed Central Ltd.

This is an Open Access article distributed under the terms of the Creative Commons Attribution License (http://creativecommons.org/licenses/by/2.0), which permits unrestricted use, distribution, and reproduction in any medium, provided the original work is properly cited.

\begin{abstract}
Background: Virus infection induces the activation and suppression of global gene expression in the host. Profiling gene expression changes in the host may provide insights into the molecular mechanisms that underlie host physiological and phenotypic responses to virus infection. In this study, the Arabidopsis Affymetrix ATHI array was used to assess global gene expression changes in Arabidopsis thaliana plants infected with Plum pox virus (PPV). To identify early genes in response to PPV infection, an Arabidopsis synchronized single-cell transformation system was developed. Arabidopsis protoplasts were transfected with a PPV infectious clone and global gene expression changes in the transfected protoplasts were profiled.
\end{abstract}

Results: Microarray analysis of PPV-infected Arabidopsis leaf tissues identified 2013 and 1457 genes that were significantly $(Q \leq 0.05)$ up- ( $\geq 2.5$ fold) and downregulated ( $\leq-2.5$ fold), respectively. Genes associated with soluble sugar, starch and amino acid, intracellular membrane/membrane-bound organelles, chloroplast, and protein fate were upregulated, while genes related to development/storage proteins, protein synthesis and translation, and cell wall-associated components were downregulated. These gene expression changes were associated with PPV infection and symptom development. Further transcriptional profiling of protoplasts transfected with a PPV infectious clone revealed the upregulation of defence and cellular signalling genes as early as 6 hours post transfection. A cross sequence comparison analysis of genes differentially regulated by PPV-infected Arabidopsis leaves against uniEST sequences derived from PPV-infected leaves of Prunus persica, a natural host of PPV, identified orthologs related to defence, metabolism and protein synthesis. The cross comparison of genes differentially regulated by PPV infection and by the infections of other positive sense RNA viruses revealed a common set of 416 genes. These identified genes, particularly the early responsive genes, may be critical in virus infection.

Conclusion: Gene expression changes in PPV-infected Arabidopsis are the molecular basis of stress and defencelike responses, PPV pathogenesis and symptom development. The differentially regulated genes, particularly the early responsive genes, and a common set of genes regulated by infections of PPV and other positive sense RNA viruses identified in this study are candidates suitable for further functional characterization to shed lights on molecular virus-host interactions. 


\section{Background}

Systemic virus infection in plants relies on complex molecular interactions between the invading virus and the host plant [1-4]. Through such interactions, the virus recruits diverse host gene products (host factors) and metabolites for the translation and replication of its genome, which disrupts the normal biological processes of the host [4-6]. On the other hand, the expression of resistance genes in the infected host is also triggered by specific molecular interactions to combat the infection. Thus, virus infection induces the activation and suppression of global gene expressions in the host [7-16]. These gene expression changes are the molecular basis of general stress and defence-like responses, viral pathogenesis and host symptom development.

Plum pox virus (PPV) is a member of potyviruses, and is considered the most devastating viral pathogen of many stone-fruit species such as Prunus persica, P. persica var. nucipersica, and $P$. domestica [6]. Despite numerous extensive screenings for genetic resistance against the virus, no natural resistant germplams are currently available for conventional breeding programs. Very little is known about the effects of PPV on host cells at the molecular level. A better understanding of molecular PPV-plant interactions would help identify key host factors required for PPV infection and assist in the development of novel recessive resistance to PPV [6].

To date, a major problem in dissecting molecular virushost interactions is the progressive and asynchronous nature of the infection in leaves or in whole plants $[1,16-$ 18]. In systemically infected plants, some cells may be infected earlier, while others may be infected later. Some parts may have higher virus titres while others may have fewer viruses or even virus-free. In the whole plant, it may take from days to weeks for the invading virus to spread from the infection site and develop systemic symptoms in the intact plant. Thus, the infected tissues contain cells at various infection stages or with viral concentrations in a wide range. As a result, temporal and spatial expression changes of host genes are very difficult to investigate. In the absence of a synchronous virus infection system and a global gene expression profiling technology, Maule and colleagues elegantly assessed the expression of selected host genes in individual cells across an advancing infection front using a cell biological approach (immunocytochemistry and in situ hybridization) (see review by Maule et al.) [17]. To date, microarray technology has been adapted to profile genome-wide gene expression changes in plants in response to infections of a number of positive sense RNA viruses [7-10,12-16]. More recently, Yang et al. [16] creatively dissected infection foci away from the noninfected tissue into four distinct zones using an infectious clone of Turnip mosaic virus (TuMV) tagged with green flu- orescence protein (GFP) (TuMV-GFP) and profiled global gene expression changes in each of these zones with microarray, making it possible to spatially and temporally correlate virus infection and accumulation with host gene expression. Collectively these works largely advance our understanding of virus-host interactions.

Considering the availability of whole genome microarrays, and increasing use of genetic and biochemical approaches in archetypal plants like Arabidopsis thaliana to explore the molecular interactions between viruses and their host plants [19], we used an Arabidopsis ATH1 Affymetrix array and analyzed global gene expression changes in Arabidopsis leaves infected with PPV at 17 days post inoculation (dpi). Further, we generated Arabidopsis synchronized single-cell protoplasts, transfected with a PPV infectious clone and assayed global gene expression changes in the protoplasts at 3, 6 and $12 \mathrm{hr}$ post transfection (hpt). The aim of this study was to investigate general gene expression changes in infected leaf tissues and their association with PPV infection and symptom development, and to identify putative host gene factors differentially regulated upon PPV infection, particularly those at early time points involved in defence and viral pathogenesis.

\section{Results and discussion Symptom development in PPV-infected Arabidopsis plants}

Susceptibility of Arabidopsis accession Col-0 to the infection of a PPV-D strain isolated in Canada was monitored by recording the development of symptoms and the virus titre. No typical viral symptoms such as mosaic, chlorosis, ringspot, vein yellowing, or leaf curling were visible in plants inoculated with PPV at $17 \mathrm{dpi}$ and up to $42 \mathrm{dpi}$. This is consistent with the recent finding that Arabidopsis plants infected by two PPV-D isolates displayed mild or no symptoms [20]. At $17 \mathrm{dpi}$, the most obvious phenotypes observed in this study were mild growth retardation, slightly delayed flowering and bolting (Figure 1A). These phenotypes were not documented for Arabidopsis accession Col-0 infected with two PPV-D isolates but were very similar to accession Bay-O inoculated with one of the two PPV-D isolates [20]. Considering the diverse phenotypes of different accession-isolate combinations, the observed phenotypic variation between the two studies is likely due to the PPV isolates used. Using reverse transcriptionpolymerase chain reaction (RT-PCR) and enzyme-linked immunosorbent assay (ELISA), PPV was detected in newly developed rosette leaves above the inoculated leaves (Figure $1 \mathrm{~B}$ ) at $17 \mathrm{dpi}$. Since PPV-induced symptoms appeared and the virus was detected by RT-PCR and ELISA at $17 \mathrm{dpi}$ in the infected leaf tissues, it was expected that changes in host gene expression would be altered at this time point. In addition, we also inoculated Nicotiana benthamiana 
A.
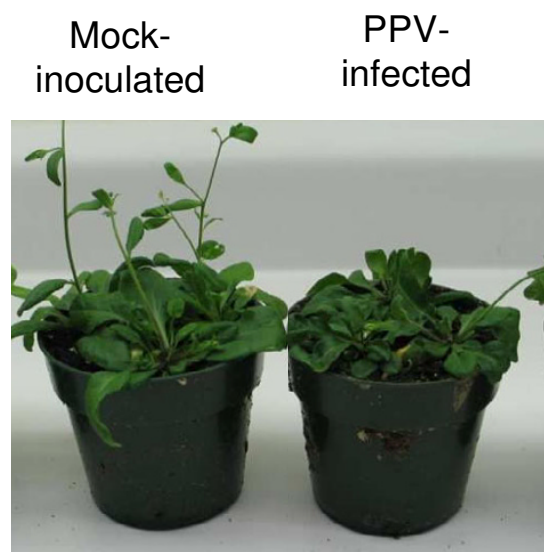

B. BR1 BR2 BR3
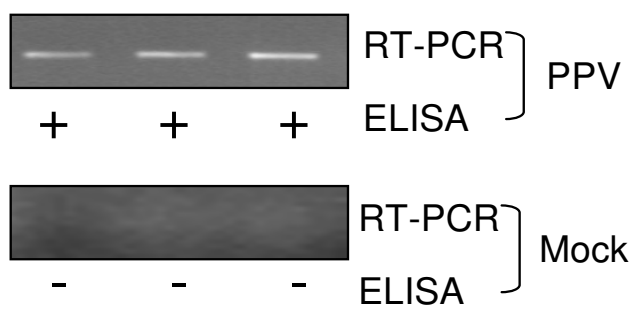

C.

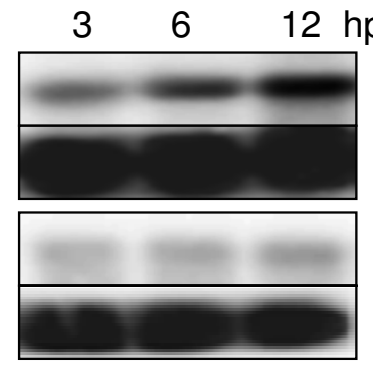

pPPV-SK68

Histone 3

PPPV-SK68

Histone 3

\section{Figure I}

Systemic infection and detection of PPV in Arabidopsis thaliana plants. (A) Symptoms on mock-inoculated (left) and PPV-infected (right) plants 17 days post inoculation (dpi). (B) RT-PCR and ELISA analysis of PPV-infected and mockinoculated leaf tissues at $17 \mathrm{dpi}$. BRI, BR2, BR3, represents three independent biological replicates of PPV-infected and mock-inoculated leaf tissues, respectively. RT-PCR amplification of a $467 \mathrm{bp}$ fragment corresponding to a segment of the PPV genome (nt 9|40 to 9607), as tested using 25 cycles of amplification. +, ELISA positive; -; ELISA negative. (C) sqRTPCR amplification of a CDNA fragment of the PPV genome isolated from Arabidopsis protoplasts transfected with PPPVSK 68 and pPPV-SK68 at 3, 6 and 12 hours post transfection (hpt), respectively. Histone 3 gene was used as a loading control. RT-PCR amplification for both panel B and C were carried out using the same RNA samples that were used in microarray hybridizations. plants with PPV. Infected leaves showed chlorosis and severe mosaic symptoms as early as $7 \mathrm{dpi}$ (data not shown). At $17 \mathrm{dpi}$, the virus titre in N. benthamiana was at least 100 times or higher than that in Arabidopsis (data not shown), suggesting that Arabidopsis may have stronger basal or inducible resistance to PPV than N. benthamiana.

\section{Over- or under-represented functional categories of differentially expressed Arabidopsis genes in PPV-infected leaf tissues}

At 17 dpi, newly expanded PPV-infected rosette leaves from the inoculated plants and the corresponding leaves from the mock-inoculated plants were sampled for microarray hybridizations. Consistency of the microarray data was assessed by comparing the mean normalized signal intensities obtained from the mock-inoculated control samples across three independent biological replicates. A high correlation $(0.96-0.98)$ among the mock inoculated control samples was observed, indicating low biological variability between the replicates.

Gene expression data were analyzed by one-way ANOVA to identify differentially expressed genes in PPV-infected rosette leaves from the inoculated plants relative to leaves from the mock-inoculated plants. Using stringent selection criteria with the Benjamini and Hochberg false discovery rate (FDR) of 5\% [21], corresponding to $Q \leq 0.05$ [22], $\sim 31.4 \%$ of the non-redundant (nr) genes $(7,151$ out of the 22,810 Arabidopsis genes printed on the chip) were identified as significantly differentially expressed (either induced or repressed) in response to PPV infection. These 7,151 genes were further filtered using a 2.5 -fold increase or decrease in signal intensity. Using this fold change cutoff, we identified 2,013 and 1,457 Arabidopsis genes that were significantly induced and repressed by PPV in systemically infected tissues, respectively.

Each identified gene was then assigned to a functional class according to the Arabidopsis MIPS (Munich Information Centre for Protein Sequences) functional classification scheme (Figure 2). With the information gathered from TAIR (The Arabidopsis Information Resource) database (please see Availability \& requirements for more information), we were able to assign a putative function for $54.3 \%$ of the total 22,810 genes on the array, while the remaining $45.7 \%$ were undefined as they were annotated as "unknowns or orphans" (Table 1). The expression levels of Arabidopsis genes significantly induced or repressed by PPV were assigned to 12 different major functional groups. In some major functional groups, genes were further separated into subcategories to simplify the data for biological interpretation [see Additional file 1]. The number of genes in each functional category was subjected to Fisher's exact test $[23,24]$ to determine if genes involved in certain biological processes were over- or 


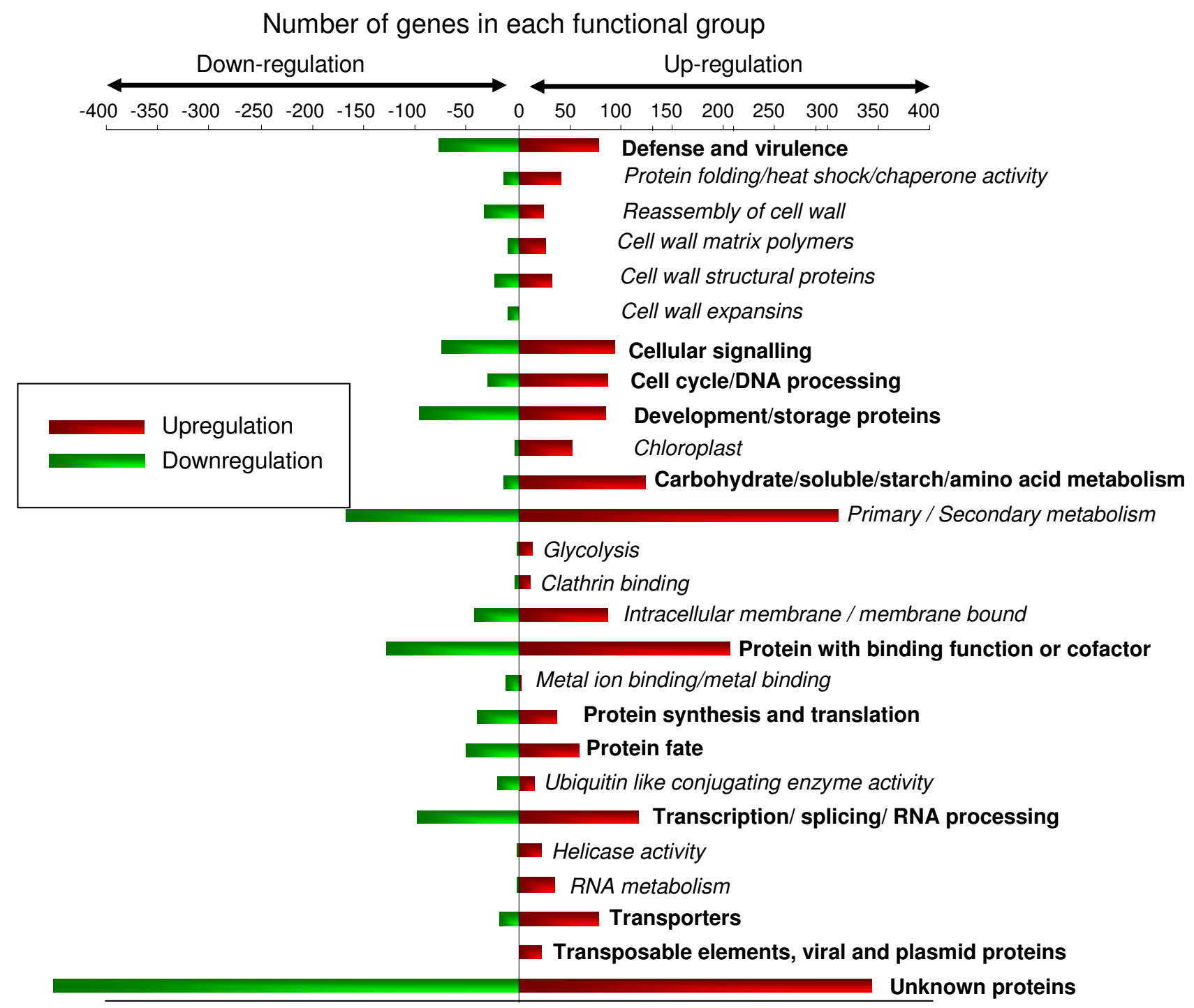

Figure 2

Functional distribution of Arabidopsis genes significantly induced and repressed in PPV-infected leaves. The genes were grouped following the methods of the MIPS http://mips.gsf.de/proj/thal/db/Arabidopsis classification scheme. Genes whose function has not been determined were grouped under "unknown function". Number of genes identified in each functional group is indicated on the $\mathrm{x}$-axis. Genes that belong to major functional categories are highlighted in bold and the subcategories within a major functional category are highlighted in italics.

under-represented $(P \leq 0.001)$. The functional groups significantly over-represented in the set of upregulated genes were carbohydrate/soluble sugar/starch/amino acid metabolism $(P<7 \mathrm{E}-12)$, primary and secondary metabolism $(P<2.2 \mathrm{E}-07)$, intracellular membrane/membranebound organelle $(P<4.5 \mathrm{E}-06)$, clathrin binding $(P<1.2 \mathrm{E}$ $05)$, glycolysis $(P<2.0 \mathrm{E}-05)$, protein folding/heat shock/ chaperone activity $(P<5.2 \mathrm{E}-06)$, cell wall-associated transcripts $(P<1.6 \mathrm{E}-05)$, RNA metabolism $(P<1.9 \mathrm{E}-05)$, chloroplast $(P<1.8 \mathrm{E}-06)$, protein fate $(P<3.5 \mathrm{E}-07)$, ubiquitin-like conjugating enzyme activity $(P<4.1 \mathrm{E}-05)$ and development/storage proteins $(P<4.8 \mathrm{E}-08)$. Among the downregulated genes, the over-represented functional groups were metal ion binding/metal binding $(P<1.6 \mathrm{E}$ $07)$, development/storage proteins $(P<3.3 \mathrm{E}-06)$, cell wall-associated transcripts $(P<0.00013)$ and protein synthesis and translation $(P<1.4 \mathrm{E}-43)$. Genes involved in primary/secondary metabolism $(P<1.4 \mathrm{E}-06)$ and intrac- 
Table I: Assignment of upregulated and downregulated genes in each functional group identified in PPV-infected Arabidopsis leaves and protoplasts.

\begin{tabular}{|c|c|c|c|c|}
\hline S.No & Functional category & $\begin{array}{l}\text { Number of genes on } \\
\text { the array a }\end{array}$ & $\begin{array}{c}\text { PPV-infected leaves Upregulated/ } \\
\text { Downregulated [Number (\%)/Number (\%)] b }\end{array}$ & $\begin{array}{l}\text { PPPV-SK68-transfected protoplasts } \\
\text { Upregulated/Downregulated [Number } \\
\text { (\%)/Number (\%)] }\end{array}$ \\
\hline A & Defence and virulence & 1488 & $204(13.7) / 165(11.1)$ & $32(2.15) / 33(2.22)$ \\
\hline B & $\begin{array}{l}\text { Cellular communication/Signal transduction } \\
\text { mechanism/transmembrane signal transduction }\end{array}$ & 1657 & $94(5.67) / 74(4.47)$ & $16(0.97) / 18(1.09)$ \\
\hline $\mathrm{C}$ & $\begin{array}{l}\text { Cell Cycle/DNA processing/chromatin regulation } \\
\text { and cytoskeleton reorganization }\end{array}$ & 771 & $87(11.3) / 30(3.89)$ & $10(1.30) / 9(1.17)$ \\
\hline $\mathrm{D}$ & Development/storage proteins & 657 & $138(21) / 100(15.2)$ & $20(3.04) / 20(3.04)$ \\
\hline$E$ & Metabolism & 4238 & $548(12.9) / 226(5.3)$ & $35(0.83) / 4$ I (0.97) \\
\hline $\mathrm{F}$ & $\begin{array}{l}\text { Proteins with binding function or cofactor } \\
\text { requirement }\end{array}$ & 921 & $210(22.8) / 139(15.1)$ & $20(2.17) / 22(2.39)$ \\
\hline G & Protein synthesis and translation & 314 & $37(11.8) / 39(12.4)$ & I $(0.32) / /(0.32)$ \\
\hline $\mathrm{H}$ & Protein fate & 647 & $77(11.9) / 69(10.6)$ & $9(1.39) / 12(1.85)$ \\
\hline 1 & $\begin{array}{l}\text { Transcription/splicing/RNA processing/ } \\
\text { modification }\end{array}$ & 1013 & $175(17.3) / 102(10.1)$ & $32(3.16) / 29(2.86)$ \\
\hline $\mathrm{J}$ & Transporters & 563 & $78(13.9) / 19(3.4)$ & $7(1.24) / 7(1.24)$ \\
\hline $\mathrm{K}$ & Transposable elements, viral and plasmid proteins & 124 & $22(17.7) / 44(35.5)$ & $8(6.45) / 21(16.94)$ \\
\hline $\mathrm{L}$ & Unknown proteins & 10417 & $343(3.3) / 450(4.3)$ & $73(0.70) / 91(0.87)$ \\
\hline
\end{tabular}

a Number of genes in a given category represented on the chip.

b Percentage was calculated based on the number of differentially regulated genes divided by the total number of genes in the functional category on the chip.

ellular membrane/membrane-bound organelle $(P<1.3 \mathrm{E}-$ 05) functional groups were significantly under-represented.

The analysis showed that that the number of upregulated genes was more than that of downregulated genes in PPVinfected Arabidopsis leaves, probably reflecting more diverse genes induced by PPV infection. This notion is supported by a disproportionate allocation in the number of altered genes in the infected leaf tissues belonging to major functional groups of metabolism, transcription/ splicing/RNA processing proteins, defence and development/storage proteins.

\section{Gene expression changes in metabolism, chloroplast and protein fate in PPV-infected Arabidopsis leaf tissues likely involved in symptom development}

Virus infections often disturb the general metabolism in the host. This includes the accumulation of soluble sugars (e.g., sucrose synthase) and starch (e.g., starch synthase), an increase in the rate of respiration, a decrease in the rate of photosynthesis and elevated levels of amino acid synthesis (e.g., amino acid permease and aminotransferase) [25-30]. In this study, we found that in PPV-infected leaves, $23 \%(124 / 548)$ of genes associated with metabolism of starch, soluble sugars and amino acids and 2.7\% $(15 / 548)$ of genes related to glycolysis showed elevated expression levels [see Additional file 1]. Appearance of disease symptoms such as chlorosis on the Cucumber mosaic virus (CMV)-infected leaf tissues in cucumber was correlated with increased glycolysis, phosphoenol pyruvate phosphate, respiration and starch accumulation, decreased photosynthesis and reduction in total protein synthesis [27]. The increased expression of these genes may result from the physical blockage of the transport path, the inactivation of sugar transport proteins or the induction of cell wall invertase [31-33]. Indeed, several cell wall invertase genes were also induced in PPV-infected leaves in this study. These data indicate that a series of intercrossing pathways involved in sugar metabolism was differentially regulated by PPV infection. It is possible that altered gene expression pathways involved in sugar metabolism might contribute to the mild symptom development observed in PPV-infected Arabidopsis leaves.

In addition to soluble sugars, starch and amino acids, PPV also induced $16 \%(87 / 548)$ of membrane-associated proteins, including proteins associated with integral membrane, plasma membrane, endoplasmic reticulum (ER), vacuole, mitochondria and peroxisomes [see Additional File 1]. Recently, membrane proteins have also been found to be upregulated in N. benthamiana plants infected with Tomato ringspot virus (ToRSV) and PPV [13]. For example, genes encoding proteins such as plasma membrane polypeptide, putative integral membrane, COPcoated vesicle membrane, clathrin protein and mitochondrial malate dehydrogenase were induced in PPV-infected Arabidopsis leaves that have similar functional identity to those upregulated in N. benthamiana plants infected with ToRSV and PPV. It is believed that many positive-strand RNA viruses replicate their genome in association with cellular membranes. Viral proteins that are required for the formation of viral replication complexes (VRCs) are often shown to be located in ER [34-36]. It would be interesting to investigate whether these upregulated membrane proteins are co-localized to VRCs. Characterization of such host membrane factors will provide useful information regarding molecular mechanisms governing membrane specificity for viral RNA replication. 
Of the upregulated genes coding for nuclear or cytosolic proteins in PPV-infected Arabidopsis leaves, two OGTs (Olinked $\mathrm{N}$-acetyl glucosamine transferase), named SEC (SECRET AGENT) and SPY (SPINDLY, a gibberellin response protein), which can potentially posttranslationally modify the viral capsid protein (CP), are very interesting. Study by Chen et al. [37] has shown that the Nterminus of the CP of PPV is modified with O-linked Nacetyl glucosamine in $N$. clevelandii, $N$. benthamiana and Arabidopsis, indicating that the modifications are not host specific. In Arabidopsis, this modification is catalyzed by SEC but not by SPY. Such modification is not essential but plays a role in the infection process [37]. SEC and SPY have partial functional redundancy in plants $[37,38]$. It is not clear whether the upregulation of SPY in PPV-infected Arabidopsis is a compensation for the loss of SEC that is used for the modification of the PPV CP.

We also observed as many as 52 chloroplast genes that were upregulated in PPV-infected leaf tissues [see Additional file 1]. These represent approximately $60 \%$ of the chloroplast genes in the Arabidopsis genome [39]. Several studies suggest that differential regulation of chloroplast gene expression is correlated to viral symptoms such as mosaic and chlorosis $[13,16]$. Recently, Dardick [13] has reported that ToRSV or PPV infection in N. benthamiana leaves induces severe mosaic and chlorosis symptoms. However, the infection of this host with Prunus necrotic ringspot virus (PNRSV) hardly induces any symptoms. Using potato cDNA chips, it has been shown that infections of ToRSV and PPV result in the suppression of 34\% (83/243) of chloroplast-related genes, while no common genes are among the induced genes in ToRSV- and PPVinfected $N$. benthamiana. In contrast to other two viruses, PNRSV infection downregulates 67\% (10/15) and upregulates 33\% (5/15) of the chloroplast-related genes [13]. Analogous to PNRSV-infected $N$. benthamiana, PPVinfected Arabidopsis leaves did not show typical viral symptoms such as mosaic and chlorosis. The induction of such a large number of chloroplast-related genes in Arabidopsis may help maintain the normal function and morphology of the infected leaf and counteract possible detrimental effects resulting from PPV infection.

In virus infected plants, protein activities are often altered through posttranslational modifications such as ubiquitination [4]. In the current study, about $9 \%$ (60 genes) of the upregulated protein fate genes encoding proteins associated with the $26 \mathrm{~S}$ proteasome were very significant $(Q \leq$ $0.05)$ and over-represented $(P<3.5 \mathrm{E}-07)$. Of the seven upregulated $26 \mathrm{~S}$ proteasome genes, two genes code for AAA-ATPase subunits including RPT3 that reside in the mature 26S proteasome [16] and five genes including $R p n 1,3$ and 6 are involved in ubiquitination. Fundamentally, the $26 \mathrm{~S}$ proteasome is known to control many bio- chemical processes by programmed degradation of regulatory protein targets [40]. Upregulation of these genes may interfere with ubiquitin-dependent reactions in plants [41]. It has been reported that, the 26S proteasome degrades the virus-encoded movement protein that facilitates the viral cell-to-cell spread [42]. Therefore, the upregulation of the $26 \mathrm{~S}$ proteasome genes may be a resistance response to PPV infection.

On the other hand, in N. benthamiana plants infected with ToRSV, about $72 \%(33 / 46)$ of the proteasome genes have been shown to be upregulated [13]. A few archetype proteasome proteins such as subtilisin-like protease, aspartyl protease, ubiquitin conjugating enzyme, F-box protein and $26 \mathrm{~S}$ proteasome regulatory subunits induced by PPV in Arabidopsis leaves are upregulated by ToRSV in N. benthamiana plants [13]. Upregulation of such protein fate and ubiquitin genes has also been observed in other studies during viral infection $[10,16,43,44]$. Study by Marathe et al. [10] has demonstrated that the induction of F-box proteins may mediate the degradation components of the CMV-Y resistance pathway. Though the above mentioned protease genes induced by PPV infection are known to function in the protein degradation, plant defence responses and hypersensitive reactions [45-47], their exact roles in PPV infection are to be elucidated.

\section{Association of the repression of development/storage proteins, protein synthesis and cell wall-related genes in Arabidopsis leaf tissues with PPV infection and symptom development}

Many virus-induced symptoms have been linked to alterations in plant hormone synthesis $[4,48,49]$. Of the 96 development/storage genes identified in this study, 10 auxin, 5 ethylene and 4 gibberellin-related genes were repressed in PPV-infected leaves [see Additional file 2]. Recent studies $[48,49]$ on TMV infection in Arabidopsis have shown that during the process of infection the TMV replicase protein interacts with a subset of Aux/IAA proteins, resulting in the activation of auxin responsive transcription factors (ARF). Such an alteration in the transcription levels of auxin-responsive genes and the disruption of host normal physiological process have shown to be associated with disease symptoms. In this study, PPV infection suppressed the expression of two such genes encoding auxin IAA proteins (At5g57420 and At1g52830). With respect to the downregulation of ethylene responsive genes, though there is no direct evidence suggesting interactions between virus and ethylene signalling components, specific viral proteins have been suggested to alter the ethylene signalling pathway [4]. For instance, the P6 protein of Cauliflower mosaic virus (CaMV) is associated with the disruption of the ethylene response pathway and this may play a key role in the induction of symptoms such as mild vein chlorosis to severe chlorosis 
and stunting [50]. In the case of downregulation of gibberellic acid (GA), a direct interaction between the Rice dwarf virus (RDV) P2 protein and the rice ent-kaurene oxidase, a key enzyme in the synthesis of GA in plants was found to be responsible for the significant reduction of GA1 in RDV-infected plants, and in the appearance of dwarf phenotype [51]. Collectively these examples demonstrate that the suppression of hormone-related genes by viruses induces symptoms through altering the host hormone and developmental signalling pathway. It would be interesting to know whether any of the observed downregulated hormone-related genes is associated with the reduced growth and delayed development of PPV-infected Arabidopsis.

Another significantly over-represented subset of genes suppressed in PPV-infected tissues includes genes coding for the protein synthesis and translation machinery [see Additional file 2]. This functional category contains 33 ribosomal subunits: 21 large, 11 small and 1 plastid specific ribosomal proteins. In the Arabidopsis genome, there are 227 ribosomal genes $[13,52]$. About $15 \%$ of these ribosomal genes were printed on the array. Based on the analysis, we observed that approximately $81 \%(27 / 33)$ of the small and large ribosomal subunit genes were significantly repressed in PPV-infected leaves.

However, an opposite trend was observed in PPV-infected $N$. benthamiana plants [13], where $80 \%(105 / 131)$ of potato ribosomal genes were upregulated. Comparison of these potato upregulated ribosomal genes in Arabidopsis through BLAST (E-value < -10) sequence similarity searches identified 55 nuclear ribosomal subunits [13]. Comparative analysis of 27 Arabidopsis nuclear ribosomal subunits that were downregulated by PPV in our study with those in Dardick's study (using Table S5 from Dardick's study for comparison) showed 8 (7 large and 1 small) Arabidopsis ribosomal subunits with an opposing trend. Since plant viruses lack protein synthesis ability, they rely on the host cell translation machinery to produce viral proteins. Thus, PPV might benefit from the upregulation of ribosomal genes in N. benthamiana which showed more susceptibility to PPV and displayed much more severe symptoms than Arabidopsis. However, at present there is no evidence to discern whether the observed downregulation of ribosomal genes is due to the stronger basal resistance of Arabidopsis to PPV infection or due to the natural intricacy of the different host responses to PPV that are diverse depending on the tissue type, time post infection, temperature, host and virus strain, or simply due to an artifact of hybridizations, given that two different platforms were used in the studies.

Cell wall-related genes are major determinants of cell morphogenesis in plants, encoding several hundreds of different structural proteins and cell wall-related enzymes $[53,54]$. In this study, 75 cell wall-related genes encoding protein for structure (23 genes), reassembly (34 genes), expansins ( 9 genes) and matrix polymers ( 9 genes) were significantly downregulated in PPV-infected leaves [see Additional file 2]. This is consistent with results observed in Arabidopsis plants infected by TuMV [16] and in rice plants infected with RDV [15]. In these studies, repression of cell wall related genes is correlated with symptom development. Of these downregulated genes, extensin is a cell wall-localized hydroxyproline-rich glycoprotein that usually forms a cross-linked network with pectin to create a highly impassable barrier against pathogens [55]. Downregulation of extensin during PPV infection suggests a decreased extensin deposition [56]. Conceivably, PPV exploits the plasmodesmata to move from initially infected cells to the neighbouring healthy cells. It is not likely that PPV cell-to-cell movement is related to the deposition of extensin. Nonetheless, the molecular mechanisms and the biological connotation underlying the downregulation of cell wall-related genes in the infected leaf remain to be understood.

In addition to the above described genes, many genes in the category of metal ion binding or metal binding were also downregulated. It is not clear if the downregulation of these genes can lead to physiological changes that are associated with PPV infection.

\section{Identification of genes differentially regulated by PPV in infected Arabidopsis protoplasts}

Resistance induced through signal transduction pathways in Arabidopsis may take place immediately after PPV infection. The Arabidopsis leaves infected with PPV at $17 \mathrm{dpi}$ contained a mixture of uninfected, infected, and postinfected cells. Thus, the spatial and temporal information on gene expression was lost. Sampling at earlier time points such as 1 or $2 \mathrm{dpi}$ can reduce the percentage of post-infected cells but will largely increase the percentage of non-infected cells. So, protoplasts have been suggested to overcome this barrier [17]. There are several advantages in using Arabidopsis protoplasts to study plant-virus interactions. First, in contrary to unpredictable infections on the leaf, synchronized protoplast cells allows for a more precise determination of gene expression. Second, a much higher proportion of the cells are infected than that in infected leaf tissues [57]. For example, we have shown that in Arabidopsis protoplasts transfected with plasmid pPPV-SK68, a PPV infectious clone, the transfection efficiency is approximately 35\% [58]. Hence, the protoplast system makes it possible to study molecular events as early as just a few hours post infection. Like other experimental systems, the protoplast system also has some limitations. Protoplasts lack the cell wall so the physiological integrity of the plant organ is disrupted. During isolation, 
transfection and culture of protoplasts, gene expression changes induced by harsh treatments such as osmotic stress, enzymatic digestion and centrifugation may mask those induced by virus infection [17]. Physiological milieu that a virus encounters in protoplast cells might be quite different from that of an intact leaf cell. Sample bias may result from the minute amounts of RNA isolated from the protoplasts and from the subsequent amplification step. However, improved technologies and experimental designs may be used to minimize the negative impact of the system [59-62]. Recently, we reported a protocol describing the isolation and transfection of Arabidopsis protoplasts for studying PPV-host interactions [58]. In order to identify early time points for profiling global gene expression changes in infected protoplast cells, a time course experiment was performed. Arabidopsis protoplasts were transfected with a PPV infectious cDNA clone, pPPV-SK68 derived from an $M$ strain and with a noninfectious deletion mutant, pPPV-SK68 as control, respectively [58]. In the mutant clone, the deletion abolishes the translation of viral proteins $\mathrm{CI}, 6 \mathrm{~K} 2$ and NIa/VPg required for PPV replication. The quantitative results showed that the viral RNA in the protoplasts was detectable at $3 \mathrm{hpt}$, accumulated at $6 \mathrm{hpt}$ and peaked at $12 \mathrm{hpt}$ (Figure 1C), followed by a decline at $24 \mathrm{hpt} \mathrm{[58].} \mathrm{The} \mathrm{time}$ course progression of PPV infection in Arabidopsis protoplasts is similar to that of Cymbidium mosaic virus (CyMV) in orchid protoplasts [63]. Thus, three time points, 3, 6 and $12 \mathrm{hpt}$ were selected for this study.

Gene expression in PPV-infected Arabidopsis protoplasts was analyzed by one-way ANOVA to identify genes differentially expressed at each time point. The degree of biological variability and reproducibility of the microarray data was assessed by comparing the mean values of the normalized signal intensity from the protoplasts transfected with a non-infectious mutant, pPPV-SK68 $\Delta$ with all three independent biological replicates at each time point. The analysis resulted with a high correlation coefficient of $0.90-0.95$, indicating low technical and biological variability between the samples used in the hybridizations. Using FDR at 5\%, we identified $~ 8.4 \%(1,907$ out of $22,810)$ of non-redundant genes that were significantly $(Q \leq 0.05)$ differentially regulated in protoplasts transfected with the PPV infectious clone, PPPV-SK68 at three different time points relative to the control transfected with the non-infectious deletion mutant, pPPV-SK68 These genes were further filtered using a 2.5-fold increase or decrease in signal intensity, resulting in $263 \mathrm{nr}$ genes that were induced ( $\geq 2.5$-fold), and 304 genes that were repressed ( $\leq-2.5$-fold), as illustrated in the Venn diagrams (Figure 3A and 3B). A comparison analysis between 263 induced and 304 suppressed genes identified 107 genes induced at one time point and were not repressed at other time points, 148 genes repressed at one time point and

were not induced at other time points, and 156 genes induced and repressed at different time points (Figure 3C) [see Additional file 3]. The analysis also revealed that the number of repressed genes was greater than that of the induced genes at all three time points analyzed. The number of genes that were commonly repressed among the time points was 14 between 3 and $12 \mathrm{hpt}, 10$ between 3 and $6 \mathrm{hpt}$, and 12 between 6 and $12 \mathrm{hpt}$. We further examined each of these 263 induced and 304 repressed genes to see if they were also consistently induced or repressed at all three different time points of infection. Fifteen genes were found to be constantly repressed and 4 were consistently induced in the PPV transfected protoplasts, suggesting that the proportion of genes repressed at all three time points were greater than that of the genes induced.

The genes induced or repressed in PPV-infected protoplasts were annotated, assigned to a predicted function

A. 263 induced genes

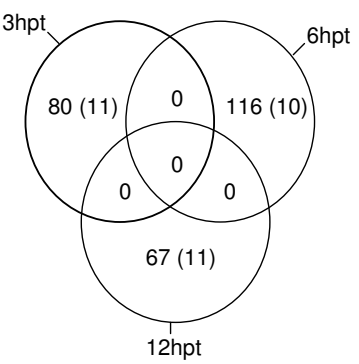

C. Overlapping genes between $A$ and $B$

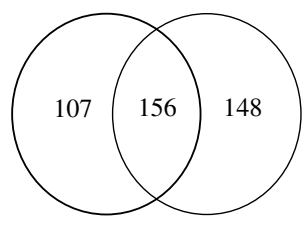

Figure 3

Venn diagrams depicting the distribution of induced ( $\geq 2.5$ fold) and repressed ( $\leq \mathbf{- 2 . 5}$ fold) genes in PPVinfected protoplasts at three different time points. A statistical cut-off with a FDR at $5 \%$ that corresponds to $Q \leq$ 0.05 , after Benjamini and Hochberg's correction was used to determine genes significantly differentially regulated in protoplasts transfected with a PPV infectious cDNA clone, pPPVSK68 at 3, 6 and 12 hours post transfection (hpt). The number of genes in the non-overlapping sector represents unique significant genes at each time point, while the overlapping sectors represent genes that are in common at time points indicated. The number in parentheses in the Venn diagram circles corresponds to the genes induced or repressed in the PPV infected leaves. 
and classified into 12 different major functional categories using the Arabidopsis MIPS functional classification scheme (Figure 4). Fisher's exact test $[23,24]$ was used to determine whether the representation of the number of genes in each functional category was significant $(P \leq$ 0.001 ) or by random chance. Of the upregulated genes, transcripts involved in primary and secondary metabolism $(P<6.2 \mathrm{E}-06)$, cellular signalling $(P<4.4 \mathrm{E}-11)$, defence response $(P<2.7 \mathrm{E}-06)$, transcription factors $(P<$ $1.1 \mathrm{E}-11)$ and transporters $(P<1 \mathrm{E}-12)$ were over-represented, while in the case of downregulation, genes involved in transcription factors $(P<5$ E-09), primary and secondary metabolism $(P<6.4 \mathrm{E}-05)$, kinases or cellular signalling $(P<1.3 \mathrm{E}-05)$, and defence responses $(P<5.6 \mathrm{E}-$ $05)$ were over-represented. A complete list of induced or repressed genes in PPV-infected protoplasts in different functional groups is provided [see Additional file 3].

As evident [see Additional file 4; Additional file 5; Additional file 6], comparison of the differentially expressed genes between PPV-infected Arabidopsis protoplasts (263 up- and 304 downregulated genes) and PPV-infected leaf tissues (2,013 induced genes and 1,457 suppressed genes) resulted in only 32 and 33 common genes that were significantly induced ( $\geq 2.5$-fold) and repressed $(\leq-2.5$ fold), respectively. A few vital genes such as genes encod-

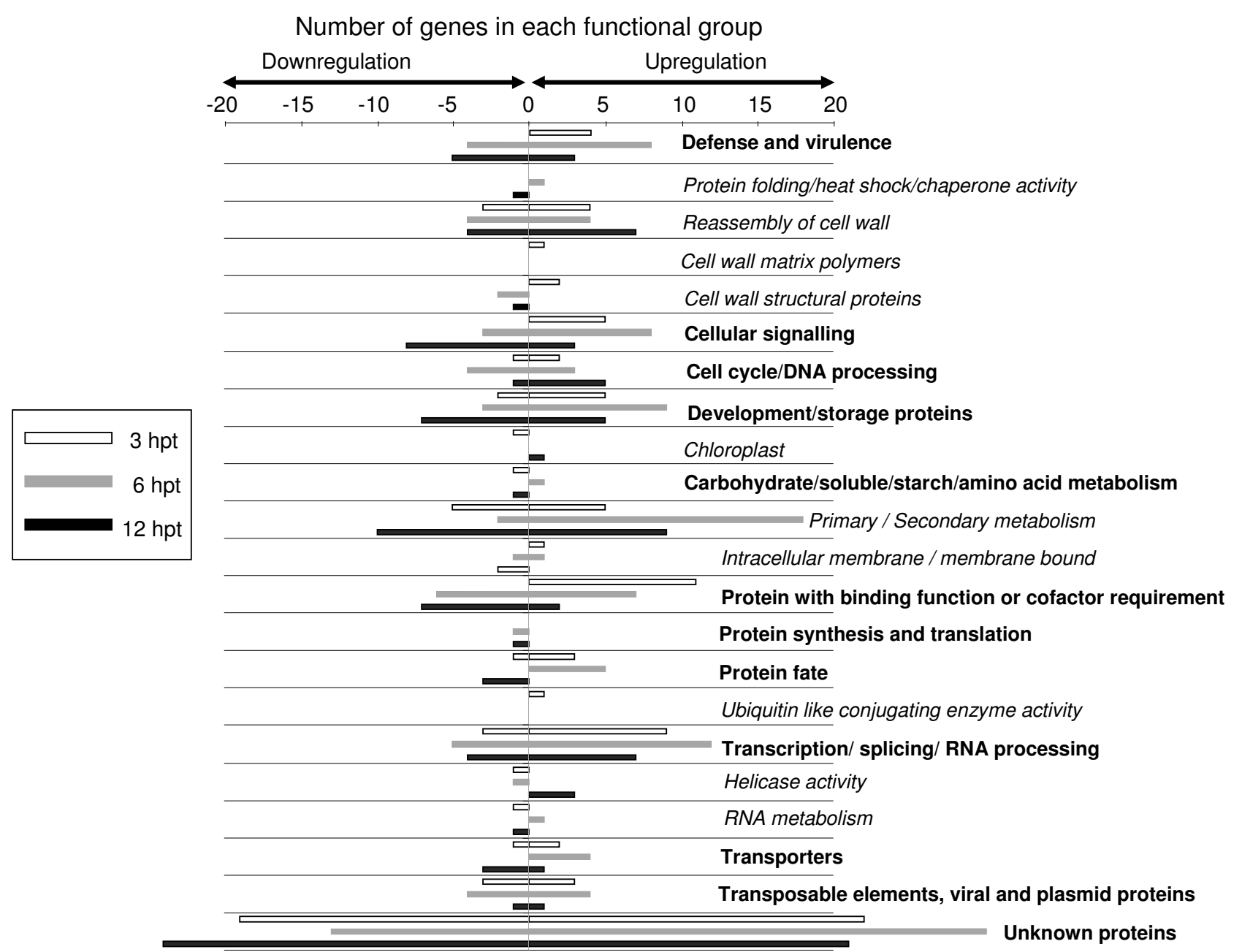

\section{Figure 4}

Functional distribution of Arabidopsis genes significantly induced and repressed in PPV-infected protoplasts. The genes were grouped following the method of the MIPS http://mips.gsf.de/proj/thal/db/Arabidopsis classification scheme. Genes whose function has not been determined were grouped under "unknown function". Number of genes identified in each functional group is indicated on the x-axis. Genes that belong to major functional categories are highlighted in bold and the subcategories within a major functional category are highlighted in italics. 
ing heavy metal protein, disease resistance protein, $\mathrm{FtsH}$ protease, cytochrome P450 and $\beta$-1, 3-glucanase were significantly differentially regulated by PPV in the infected leaves and transfected protoplasts. The smaller percentage of significantly differentially regulated genes observed in the PPV-infected protoplasts than in the PPV-infected leaf suggests a remarkable gene expression differences between the two systems. However, as discussed above, the differences in the alteration of gene expression changes in the protoplasts induced by PPV infection could have been masked by harsh treatments during protoplast isolation, transfection and culture or might result from the two different PPV strains used. Though the PPV-D and -M strains used in this study share more than $95 \%$ sequence identity [64], these two strains may induce different symptoms on the same host $[20,65]$.

To visualize gene expression profiling at all three time points, a hierarchical clustering analysis was carried out on the 263 induced and 304 repressed genes (Figure 5A). A gene tree heat map was built using Pearson correlation distance metric with an average linkage algorithm. To understand further the temporal relationship of the host gene expression in PPV-infected protoplasts at each time point, twelve distinct groups of expression pattern clusters were generated on the significant differential gene expression datasets using K-means clustering with Pearson correlation distance metric (Figure 5B) [see Additional file 7]. A complete list of genes induced or repressed at each time point in different cluster groups along with their expression levels and putative functions is provided [see Additional file 8]. The clustering analysis also revealed greater changes in gene expression (236 genes) at $6 \mathrm{hpt}$ than at 3 hpt (163 genes) and at 12 hpt (201 genes) in PPV-infected Arabidopsis protoplasts. These observations suggest that early gene expressions in response to PPV infection are active and dynamic.

\section{Early upregulated genes related to disease resistance or defence responses in PPV-infected Arabidopsis protoplasts}

PPV infection in protoplasts induced the expression of 263 genes. In contrast to about $11 \%$ of the suppressed genes that were common at different time points, there were no induced genes shared at different time points, suggesting induction of host gene expression was much more transient than suppression. Genes related to defence, cellular signalling, primary and secondary metabolism, transcription and transporters were upregulated and over-represented. Within these five categories, $\sim 52 \%(48 / 93)$ of genes were predominantly upregulated ( $\geq 2.5$-fold) at 6 hpt [see Additional file 3]. Examples of the upregulated genes in the above functional categories include MADS box protein, zinc finger family protein, WRKY family transcription factor, avirulence (Avr)- induced protein, hydrophobic protein, disease resistance TIR-NBS-LRR (toll-interleukin-1-receptor/nucleotidebinding site/leucine-rich repeat), protein kinases and phosphatases.

Another interesting gene upregulated by PPV encodes a disease resistance protein, TIR-NBS-LRR. This gene was upregulated with 6.39-fold in PPV-infected protoplasts at 6 hpt and 2.12-fold at $12 \mathrm{hpt}$, and 10.84-fold in PPVinfected leaves [see Additional file 4]. In the Arabidopsis (Col-0 accession) genome, there are 149 NBS-LRR-like genes $[66,67]$. The resistance gene NBS-LRR mostly confers resistance to viral diseases but not necessarily associates with cell death or tissue necrosis [66]. Genes Sw5, N and $R x$ are homologous to the NBS-LRR gene. $R x$ resistance to Potato virus X (PVX; Potexvirus) is the most classical example, which shows an extreme resistance that inhibits virus replication without hypersensitive cell death [68]. The Sw5 gene confers resistance to several Tospoviruses [69], and $N$ and $R x$ are effective against many natural variants of TMV and PVX [70,71]. Since the specificity determinants subsist in LRR domains [66], it would be interesting to find out if the NBS-LRR gene detected in the PPV-infected leaf plays a role in resistance responses to PPV infection.

The comparison of induced genes at different time points in PPV-infected protoplasts revealed that genes upregulated at $3 \mathrm{hpt}$ might regulate their target genes at $12 \mathrm{hpt}$. For instance, two genes coding for cnd41 (At5g24820), a plastid specific DNA binding factor, and calmodulin (At3g15050, At3g16490), a signalling binding protein were induced at $3 \mathrm{hpt}$ and their target genes encoding metabolic enzymes such as serine carboxypeptidase (At1g11080) were upregulated at 12 hpt $[57,58]$. Similarly, transcription factors such as zinc finger proteins (At5g54020; At3g45480; At4g12140) was upregulated at $3 \mathrm{hpt}$ and the genes encoding enzymes such as GDSLmotif lipase (At3g43550) and glycosyl hydrolases (At3g26140, At4g39010) were upregulated at $12 \mathrm{hpt} \mathrm{[72].}$ These results suggest that virus infection may induce expression of specific upstream regulator genes first which then activate the expression of downstream target genes.

\section{Inhibition of host mRNA accumulation in PPV-infected protoplasts}

Based on the expression analysis (Figure 3), the number of repressed genes in the transfected protoplasts was greater than that of the genes induced at all time points, suggesting that at early infection stages, suppression is more active than induction of host gene expression. Moreover, about $11 \%$ (33 out of 304) of the suppressed genes overlapped at different time points, indicating a relatively stable suppression of genes. Consistent with this, in pea cotyledons infected with Pea seed borne mosaic virus 


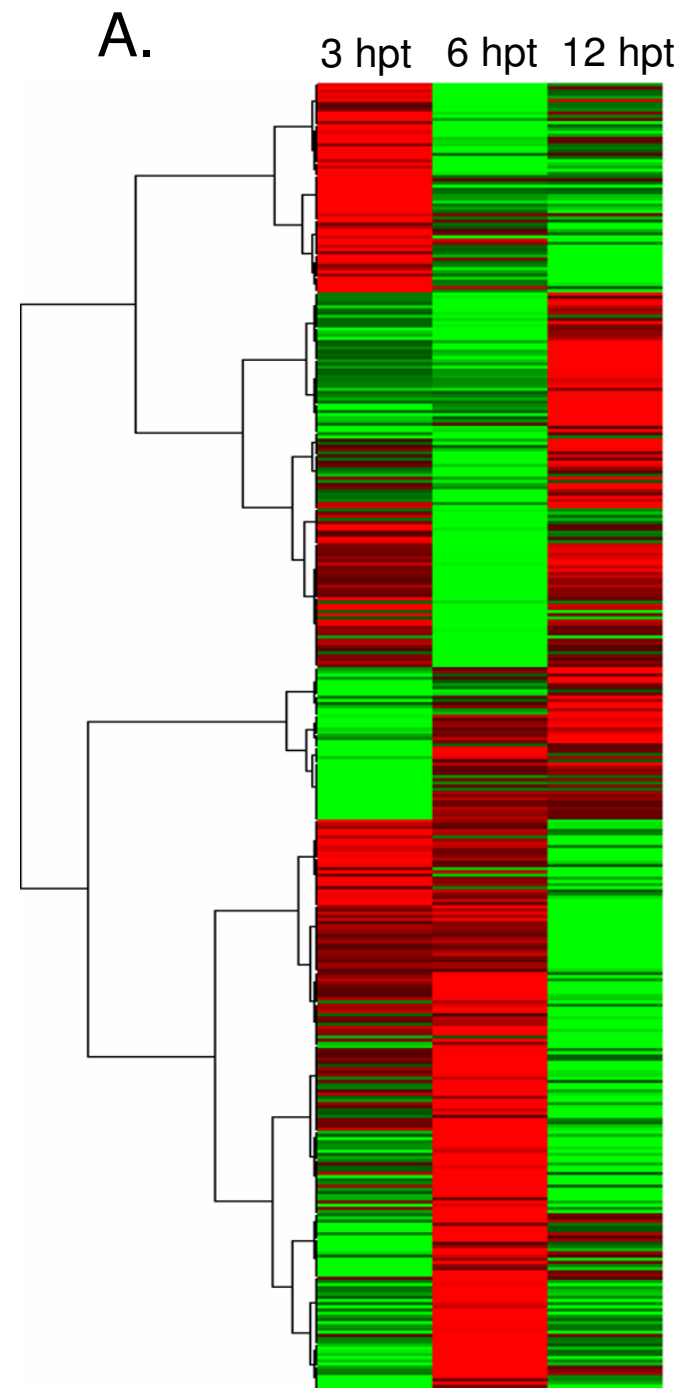

Fold suppression

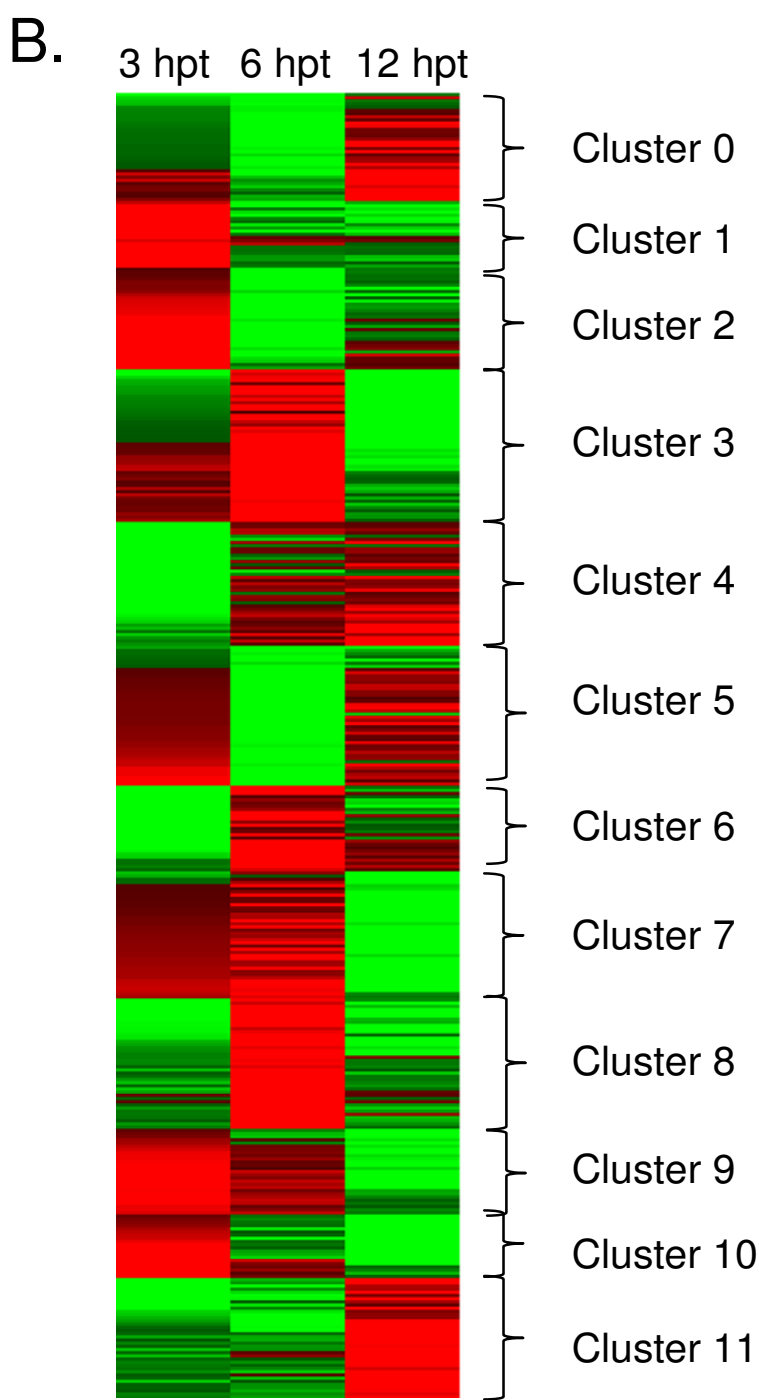

Fold induction

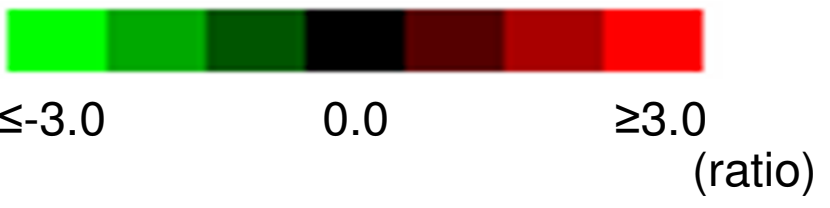

Figure 5

Clustering analysis of differentially regulatedgenes in PPV-infected Arabidopsis protoplasts. (A) Hierarchical clustering and changes in gene expression of $4 \mathrm{II}$ significantly $(Q \leq 0.05)$ differentially regulated genes in PPV-infected Arabidopsis protoplasts at 3, 6 and 12 hours post transfection (hpt). Gene tree map generated from 4 II significantly differentially regulated Arabidopsis genes are derived from 263 upregulated and 304 downregulated genes. (B) Using k-mean clustering, the gene expression profiles were grouped into twelve major cluster groups. The expression pattern of a gene in a cluster group is indicated in parentheses. Expression levels are color coded with red indicating upregulation by PPV infection; green indicating downregulation by PPV infection; and black indicating no change in expression. The intensity of color represents the degree of gene expression levels. List of genes induced or repressed at each time point in different cluster groups along with their expression levels and putative functions is provided in [Additional file 8]. 
(PSbMV), suppression of diverse host genes including seed storage proteins (e.g., vicilin and convicilin), and starch synthase occurs only in a zone of six to eight cells immediately behind the infection front, which coincided with the onset of viral replication [73]. In the present study, a gene coding for the seed storage protein cupin family (At2g18540) that shares sequence homology to the pea vicilin and convicilin was significantly repressed by PPV infection at $12 \mathrm{hpt}$ in Arabidopsis protoplasts. Suppression of such host gene expression or "host shutoff" has been suggested to be due to stress responses, induced defence states or a mechanism employed by viruses to outcompete against host mRNAs for host resources for their translation and replication $[16,17,43,74]$. Study by Rottier [75] has demonstrated that protein synthesis in protoplasts is blocked in cowpea protoplasts transfected with Cowpea mosaic virus. Despite this inhibition, viral mRNAs are preferentially translated. Since both viruses and hosts share the same translational apparatus, viruses must have a mechanism to avoid this inhibition. It is not clear whether the disappearance of host mRNAs is the consequence of mRNA destabilization triggered by stress response, or host transcription inhibition by the virus, or targeted degradation through a virus-induced ribonuclease activity.

\section{Identification of a common set of genes in general stress and defence-related groups differentially regulated by infections of PPV and other positive sense RNA viruses}

We performed a cross sequence comparison analysis by blasting individual sequence of all the genes significantly differentially regulated by PPV in infected Arabidopsis leaves against 2,156 uniEST sequences derived from PPVinfected $P$. persica leaves [64]. High-scoring pair (HSP; $\geq$ 100 score) and E-value (E-value $\leq 10-20$ ) were used to identify orthologs. A total of 170 induced [see Additional File 9] and 18 repressed Arabidopsis genes showed high sequence similarity to $P$. persica uniESTs. Of these 170 induced genes, approximately 39\% (67/170) and 16\% $(28 / 170)$ of the genes were involved in metabolism and defence, respectively. The defence-related genes include those coding for pathogenesis related (PR)-proteins, heat shock and germin-like proteins (Ger2) [see Additional file 9]. An increased expression of PR proteins requires salicylic acid (SA) signifying that compatible host-virus interactions induce defence-like responses through a SA dependent pathway [76]. More recently, it has been shown that PPV infection in the apoplastic space of $P$. persica leaves induces a thaumatin-like protein (PR-5) [77]. Induction of such protein is thought to be mediated by an increase in the level of peroxidase accumulation [77]. A similar trend was also observed in PPV infected Arabidopsis leaves where genes encoding PR-5 and peroxidase were significantly induced and their counterparts were also found in the uniEST sequences derived from PPV-infected P. persica.

To determine whether the diverse RNA viruses have the ability to elicit common gene expression changes, we cross-compared the genes that were significantly differentially regulated by PPV infection in this study [Additional file 1] [Additional file 2] to those Arabidopsis genes that were differentially regulated by infections of other positive sense RNA viruses including CMV [9,10]; TMV [7]; TuMV, and Oil seed rape mosaic virus (ORMV) [16], and to five diverse RNA viruses, i.e., TuMV, ORMV, Turnip vein clearing virus (TVCV), Potato virus X (PVX), and CMV [8]. Collectively, 416 common genes [see Additional file 10] were identified from this analysis. These genes were further classified into 6 different categories. Group A contains 202 genes induced by infections of PPV and other positive sense RNA viruses. About $40 \%$ (80/202) are metabolic genes and $~ 8 \%(17 / 202)$ are defence-related genes. Group B includes 41 Arabidopsis genes that were induced during PPV infection but repressed by infections of other positive sense RNA viruses. About 27\% (11/41) are involved in metabolism. Group C comprises of 119 Arabidopsis genes repressed during PPV infection but induced by infections of other positive sense RNA viruses. For example, a defence-related gene encoding glycosyl transferase (At1g70090), which was repressed in PPVinfected leaves at $17 \mathrm{dpi}$ was observed to be induced more than 1.5-fold in TMV-infected leaves [7] at 14 dpi. Group D consists of 7 Arabidopsis genes repressed by infections of PPV and other positive sense RNA viruses. Group E comprises 25 genes that were induced during PPV infection but either induced or suppressed by infections of other positive sense RNA viruses. Group F contains 22 Arabidopsis genes repressed during PPV infection but induced during infections of more than one positive sense RNA virus. Previous studies have revealed that in virus-infected Arabidopsis and tomato leaves as many as one-third of the genes commonly induced by viruses are known or predicted to be involved in plant defence- and stress-related genes $[5,15]$. In the current study, about $52 \%(217 / 416)$ of the functional proteins differentially regulated in response to infections of PPV and other positive sense RNA viruses are involved in defence, cellular signalling and metabolism. Twenty-nine cellular signalling genes involved in defence mechanisms including protein kinase (At3g08760, At4g32250), protein phosphatase 2C (At5g02760, At3g05640), pyruvate kinase (At2g36580), serine/threonine protein kinase (At3g17410) and calmodulin-binding family protein (At5g62390) $[3,78,79]$ were induced by infections of PPV and other positive sense RNA viruses. Substantial induction of these defence, cellular signalling and metabolism genes by PPV and other positive sense RNA viruses in infected leaf tissues suggests that there is a shared pathway modulating their expression. 


\section{Validation of microarray data by semi-quantitative RT- PCR (sqRT-PCR) and Northern hybridizations}

Since most changes in gene expression occurred at $6 \mathrm{hpt}$, 9 transcripts significantly upregulated and 1 transcript significantly downregulated at 6 hpt were selected to validate the microarray data using sqRT-PCR. We also selected 3 other transcripts that were significantly upregulated at 3 or 12 hpt for validating the microarray data through sqRTPCR. We further confirmed the microarray data of 5 Arabidopsis genes that were differentially regulated in both PPV-infected protoplasts and leaves using sqRT-PCR or Northern hybridizations. Overall, the expression patterns of all the 13 genes analyzed by sqRT-PCR were consistent with those by microarray hybridizations (Figures 6 and 7) [see Additional file 11]. However, the relative levels of gene expression obtained from sqRT-PCR or Northern hybridizations were lower than those from microarray hybridizations. This inconsistency could have been attributed to several factors: the differences in the efficiencies of reverse transcriptase, the low copy of an mRNA transcript and the different priming methods or the fundamental differences in data normalization procedures between microarray and Northern hybridizations or sqRT-PCR. For example, in this study, the former was achieved through the global normalization, while the later used the expression of the housekeeping gene Actin to normalize the sqRT-PCR or Northern blots. So, application of normalization criteria might have an effect in the correlation of fold changes between these two methods [80,81]. Though the housekeeping gene Actin was considered to be constitutively expressed in tissues, due to the nature of the processing of hybridizing samples to Northern blots, one could reasonably assume a possible inconsistency resulting from these two methods. Certainly, other sensitive techniques such as quantitative RT-PCR (qRT-PCR) and nuclear run-on assays can be used further to validate the results generated from these expression studies.

\section{Conclusion}

Microarray analyses conducted in this study allowed us to gain insights into global gene expression changes in Arabidopsis associated with PPV infection, symptom development and defence responses. At $17 \mathrm{dpi}$, PPV displayed mild growth retardation, slightly delayed flowering and bolting. PPV infection was associated with the downregulation of genes related to development/storage proteins, protein synthesis and translation and cell wall-related genes and the upregulation of genes involved in soluble sugars, starch, amino acid, intracellular membrane/membrane-bound organelles, chloroplast and protein fate. Transcriptional profiling of PPV-infected protoplasts revealed that at early infection stages, downregulation of host gene expression was more prominent than upregulation. Concomitant with this downregulation, several defence and cellular signalling genes were induced during
PPV infection. These genes may be involved in signal transduction pathways to induce resistance to combat the virus. Further targeted functional studies of these early defence-related genes will help unravel their biological function during the course of PPV infection.

\section{Methods}

Plant growth and virus inoculation

Arabidopsis thaliana accession Col-0 was grown in a growth chamber at $80 \% \mathrm{RH}$ with a day/night regime of $16 \mathrm{~h}$ light at $22^{\circ} \mathrm{C}$ followed by $8 \mathrm{~h}$ dark at $18^{\circ} \mathrm{C}$. Prior to the preparation of viral inoculum, leaf tissues collected from Prunus glandulosa infected with a Canadian PPV-D isolate were tested positive by ELISA and by RT-PCR. The inoculum was then prepared by homogenizing approximately $1 \mathrm{~g}$ of P. glandulosa leaf tissues infected with PPV-D in $10 \mathrm{ml}$ inoculation buffer $\left(\mathrm{PO}_{4}\right.$ buffer, $\mathrm{pH} 7.4$ containing $2 \%$ PVP-40 (w/v) and 0.2\% diethyl dithiocarbonic acid). Viral inoculum was mechanically rub-inoculated onto Arabidopsis leaves at 5-6 leaf stage. Control plants were mock inoculated with extracts from healthy $P$. glandulosa leaf tissues ground in inoculation buffer. All the mock- and PPVinfected Arabidopsis plants used in the microarray experiment were randomized and grown in different locations within a greenhouse under the same growth conditions. Fifty fully expanded rosette leaves above the inoculated leaves were harvested from 25 infected or mock inoculated control plants at $17 \mathrm{dpi}$. The leaves were immediately frozen with liquid nitrogen and stored at $-80^{\circ} \mathrm{C}$ prior to RNA extraction. Six independent hybridizations were performed using total RNA isolated from three independent biological replicates of the virus-infected or mockinoculated control samples.

\section{PPV infectious cDNA clone and its deletion mutant}

The PPV infectious cDNA clone pPPV-SK68 derived from an $\mathrm{M}$ strain was a kind gift from Drs. Laszlo Palkovics and Ervin Balazs, Agricultural Biotechnology Center, Hungary. A control plasmid, pPPV-SK684, was generated by deleting 1489 nt Sma I cDNA fragment from nt 4272 to 5760 (inclusive). This deletion resulted in the frame-shift of the portion of PPV genome after nt 5760 [58]. The deletion region abolishes the translation of the viral protein domains CI-6k2-NIa/VPg-NIa/Pro-NIB-CP which is required for viral replication. Thus, clone PPPV-SK68 $\Delta$ is non-infectious.

\section{Protoplast isolation and transfection}

Protoplasts were isolated using fully expanded leaves of 3week-old Arabidopsis accession Col-0 and transfected with the PPV infectious cDNA clone or the mutated PPV cDNA clone following the protocol we have developed recently [54]. Transfected protoplasts were incubated at room temperature for $5 \mathrm{~min}$, and then transferred to $25^{\circ} \mathrm{C}$ and incubated in the dark for 3, 6 and 12 h, respectively. At selected 

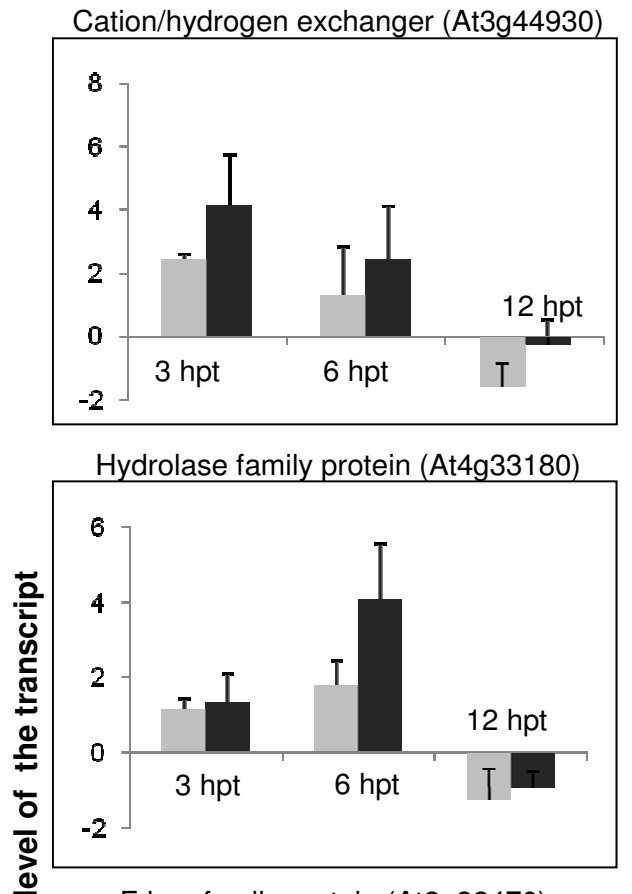

F-box family protein (At2g32470)

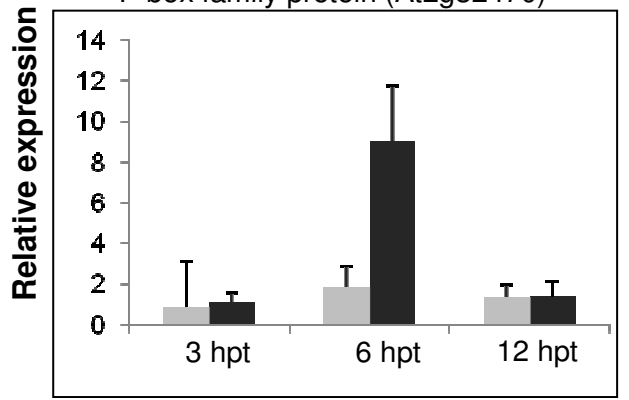

MAP Kinase (At1g32320)

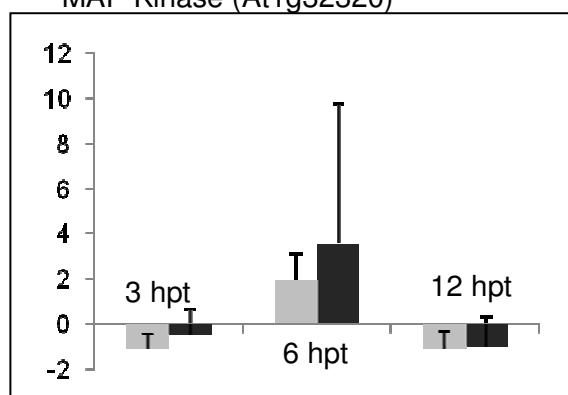

Avirulence induced gene (AIG) (At2g24390)

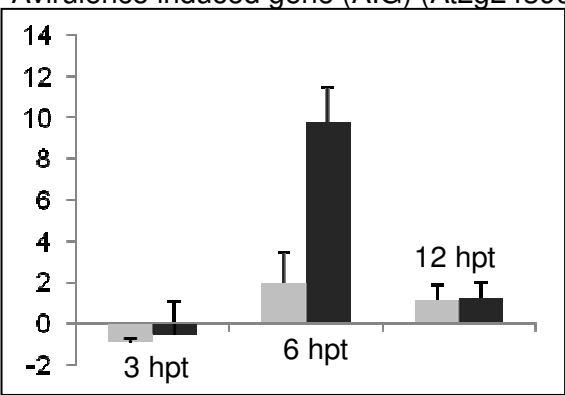

Protein Kinase PK1 (At5g40030)

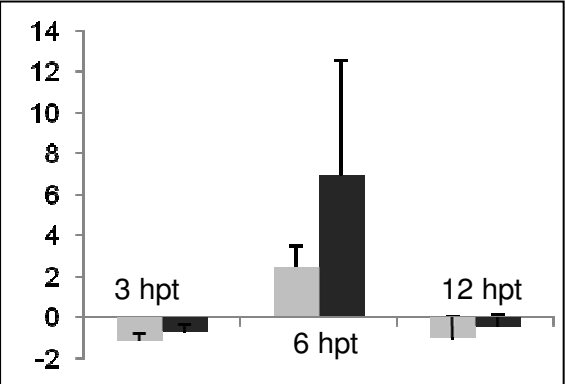

Heat shock transcription factor (At5g54070)

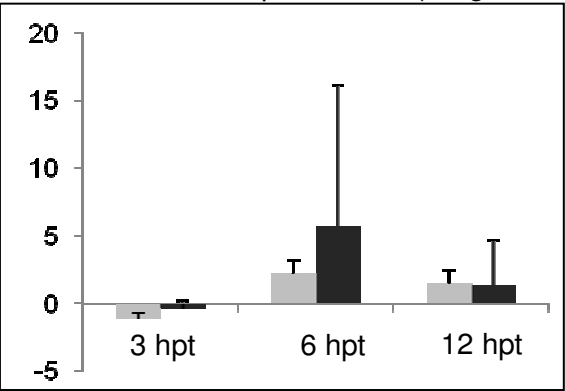

Disease resistance protein (At4g19470)

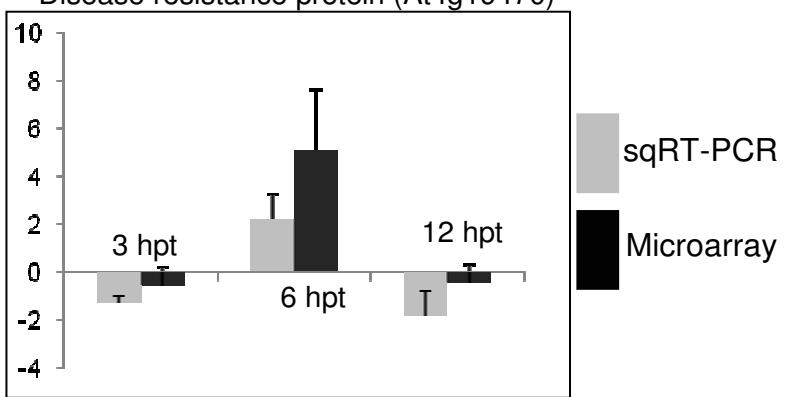

Hours post transfection (hpt)

\section{Figure 6}

Confirmation of relative expression levels of the transcripts selected from the microarray analysis with semi quantitative RT-PCR (sqRT-PCR). Expression changes of 8 selected genes were determined by sqRT-PCR and microarray. The signal intensity of each transcript was normalized using At3gl8780 (Actin 2). The Arabidopsis Genome Initiative (AGl) locus identifier of each gene is provided. The $y$-axis indicates the normalized expression level of the transcript. The $x$-axis represents hours post transfection. Expression ratios are the average of three independent hybridizations \pm standard deviation (SD). hpt, hours post transfection; dpi, days post inoculation. The error bars represent the standard deviation for the signals from each of the three independent hybridizations. 


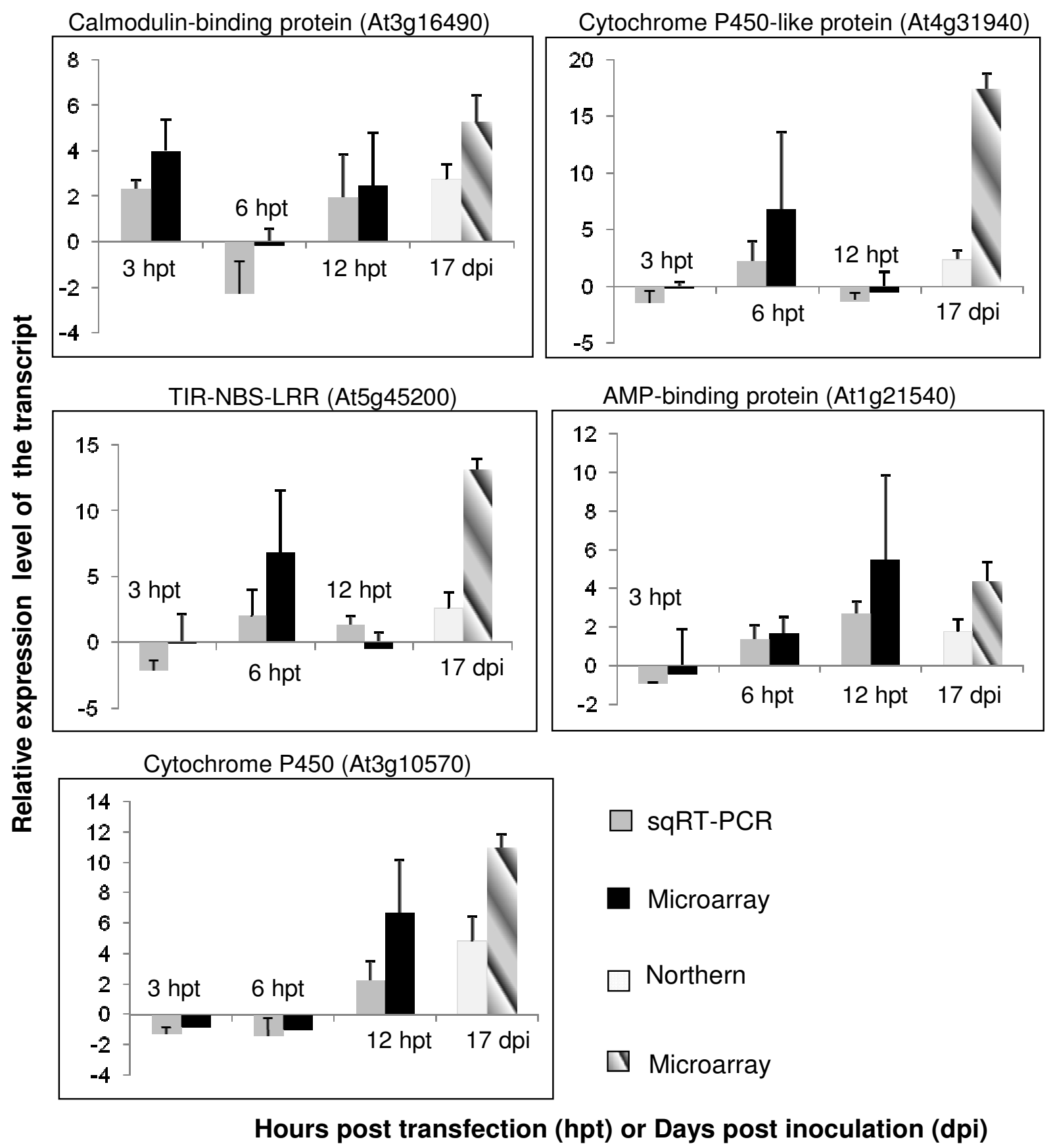

Figure 7

Confirmation of relative expression levels of the transcripts selected from the microarray analysis with semi quantitative RT-PCR (sqRT-PCR) or Northern blot hybridizations. Expression changes of 5 selected genes were determined by sqRT-PCR, microarray and Northern blot. The signal intensity of each transcript was normalized using At3gl8780 (Actin 2). The Arabidopsis Genome Initiative (AGI) locus identifier of each gene is provided. The $y$-axis indicates the normalized expression level of the transcript. The $\mathrm{x}$-axis represents hours post transfection or days post inoculation. Expression ratios are the average of three independent hybridizations \pm standard deviation (SD). hpt, hours post transfection; dpi, days post inoculation. The error bars represent the standard deviation for the signals from each of the three independent hybridizations. 
time points, transfected protoplast cells were harvested, immediately frozen in liquid nitrogen and stored at $-80^{\circ} \mathrm{C}$ prior to RNA extractions. Gene expression differences were averaged out by pooling six RNA samples isolated independently from protoplasts transfected with pPPVSK68 and pPPV-SK68 $\Delta$ at each time point after transfection. For time course comparison, three independent biological replicates were maintained. Thus, for three different time points, 18 gene chips in total were used to hybridize with RNA isolated from protoplasts transfected with PPPV-SK68 and PPPV-SK68.

\section{RNA extraction, purification and virus detection}

Total RNA from virus-infected and mock-inoculated leaves of Arabidopsis plants and from protoplasts transfected with pPPV-SK68 and pPPV-SK68 were isolated using Trizol reagent (Invitrogen) following the manufacturer's suggestion. Total RNA was purified using RNeasy Mini columns (Qiagen) after DNase I treatment (Invitrogen). Integrity of total RNA was assessed using Bioanalyzer 2100 (Agilent Technologies, Boblingen, Germany). Primers OL-PPVDF3 (5'TCAATGGAATGTGGGTGATGA 3') and OL-PPVDR6 (5' GATTAGACTCTCACCCAGGTA 3'); and PPVMF18 (5' GGAAATTGAGAGATACCT 3') and PPVMR16 (5' TTTGTCTAAAAGTGGGTTT 3') were used to detect PPV in the virus-infected or mock-inoculated control samples and in pPPV-SK68- and pPPV-SK68 4 -transfected protoplasts, respectively.

\section{Target preparation and hybridization}

Standard RNA processing and hybridization protocols were followed as recommended by the Affymetrix manual (Santa Clara, CA, USA). A double-amplification approach (Affymetrix) was used to generate cRNA for hybridization. Total RNA isolated from virus-infected or mock-inoculated leaves were subjected to double-amplification. Labelling, hybridization and detection of hybridization signals were performed at the McGill University and Genome Quebec Innovation Centre (please see Availability $\&$ requirements for more information).

\section{Data analysis}

Hybridization signals obtained from the scanned array images were quantified using MAS5.0 expression analysis algorithm, implemented in the Affymetrix GCOS (GeneChip ${ }^{\varpi}$ Operating) software version 1.2. Raw MAS5.0 data files obtained from scanned array images were imported into GeneSpring microarray analysis software version 7.3.1 (Silicon Genetics, Redwood City, CA, USA). Systemic variations across the chips were normalized using per gene and per chip normalization methods available in the GeneSpring software. Mean normalized value of the signal intensity for each gene in three biological replicate experiments was adopted as the expression value of the gene. The significant changes in gene expression during
PPV infection in infected leaves and in protoplasts were determined using $P$ values $(P \leq 0.05)$ derived from oneway ANOVA and the significant changes in the values of the identified genes were further adjusted using multiple testing correction of the Benjamini and Hochberg false discovery rate procedure [21] which applied a stringent cut off of 0.05 that corresponds to $Q \leq 0.05$ [22]. This multiple testing correction procedure is used to correct for the occurrence of false positives and to maximize the likelihood of finding significant gene sets. In order to identify genes that show significant changes of transcript levels during virus infection, we further searched for genes that were significantly up- ( $\geq 2.5$-fold) or downregulated $(\leq$ 2.5 -fold) relative to the control. For clustering analysis, gene expression profiles from the protoplasts transfected with the PPV infectious clone at each time point were clustered based on their similarity in expression using hierarchical average linkage algorithm and Pearson correlation distance metric implemented in the Cluster 3.0. The clustering results were visualized by a gene tree heat map using the TreeView program [82]. K-means clustering was employed to cluster the gene expression data from the PPV transfected protoplasts into several distinct expression profiles using Pearson correlation distance metric. The microarray data from this work was submitted to the NCBI database with Gene Expression Omnibus (GEO) accession number [GSE11217].

\section{Functional categorization of genes}

Each gene was assigned with a putative function by blasting the AGI probe identifier sequences against the Arabidopsis database deposited at TAIR (the Arabidopsis Information Resources) using the BLASTX program. Functional classification was performed by assigning the function of each gene based on protein sequence similarity using MIPS (Munich Information Centre for Protein Sequences; please see Availability \& requirements for more information) Arabidopsis functional classification schema. Genes without a category name or with unclear classification were labeled as "unknowns". Over-or underrepresentation of genes involved in each functional group was evaluated using Fisher's exact test function $[23,24]$.

\section{Determination of P. persica orthologs to Arabidopsis genes induced by PPV}

The PPV-infected P. persica leaf (PPL) EST library [64], consisting of 2156 uniEST sequences extracted from NCBI dbESTs [GenBank: DN552797, DN556565] were formatted so that they were searchable using the tBLASTx algorithm. Sequences of 2013 PPV induced and 1457 PPV repressed Arabidopsis transcripts in infected leaf tissues respectively were aligned to this collection to search for the presence of $P$. persica orthologs using the tBLASTx algorithm with default settings [83]. The BLAST output for each transcript was then parsed for high-scoring pair 
(HSP) and the associated E-value. Any hits with HSP 100 and E-value $10^{-20}$ were taken as an indicative of significant similarity [84].

Cross comparison of genes differentially regulated by PPV infection against the Arabidopsis genes differentially regulated by infections of other positive sense $R N A$ viruses The Arabidopsis genes differentially regulated in PPVinfected leaf tissues were cross compared by searching against the Arabidopsis gene set that were differentially expressed in response to the infection by other positive sense RNA viruses [7-10,16].

\section{Northern hybridizations and semi quantitative RT-PCR (sqRT-PCR)}

Northern hybridizations and sqRT-PCR were carried out to verify the microarray data. Probes for sqRT-PCR and Northern hybridizations were generated by PCR amplification of Arabidopsis cDNA with gene specific primers (Table 2). Arabidopsis Actin 2 (ACT2; At3g18780) was used as an internal control with the following primer sets; 5' GCCATCCAAGC TGTTCTCTC 3' and 5' GAACCACCGATCCAGACACT 3 ' to normalize small differences in template amounts. For Northern hybridization, $10 \mu \mathrm{g}$ of total RNA was denatured with glyoxal, electrophoretically separated on $1.5 \%$ agarose gels, blotted onto a nylon membrane and UV cross-linked $\left(1200 \mu \mathrm{J} / \mathrm{cm}^{2}\right)$. For sqRTPCR, amplicons of RT-PCR were electrophoretically separated on a $1 \%$ agarose gel, transferred to a nylon membrane by capillary blotting and cross-linked as above. Hybridizations for Northern blots and sqRT-PCR were performed with at least three independent biological replicates. The probes were radiolabeled with $\left[\alpha_{-}{ }^{32} \mathrm{P}\right] \mathrm{dCTP}$ by Ready-To-GO DNA labeling kit following the manufacturer's instructions (Amersham Biosciences). A Phosphor Imager (Imaging Screen K, Personal Molecular Imager ${ }^{\circledR}$ FX, Bio-Rad) and Quality One Quantitation software v. 4.2 (Bio-Rad) were used for visualization and quantification of radioactive signals.

\section{Availability \& requirements}

The Arabidopsis Information Resource: http://www.arabi dopsis.org/

McGill University and Genome Quebec Innovation Centre: http://genomequebec.mcgill.ca

Table 2: Primers used in semi quantitative RT-PCRa and in Northern hybridzations ${ }^{b}$

\begin{tabular}{|c|c|c|c|c|}
\hline Probe set IDs ${ }^{c}$ & AGIdocus & Description & Forward Primer (5'---3') & Reverse Primer (5'---3') \\
\hline \multicolumn{5}{|c|}{ A. Genes induced only in PPV-infected Arabidopsis protoplasts } \\
\hline 256487_at & Atlg31540 & $\begin{array}{l}\text { Disease resistance protein, TIR-NBS- } \\
\text { LRR class }\end{array}$ & $\begin{array}{l}\text { GCCAGTAGAGCTCGAGGTAA } \\
\text { AATG }\end{array}$ & $\begin{array}{l}\text { AGGCTCTTCACTGTGTTCAAT } \\
\text { CTC }\end{array}$ \\
\hline 246338_s_at & At3g44930 & $\begin{array}{l}\text { Cation/hydrogen exchanger } \mathrm{CH} \times 10 \text {, } \\
\text { putative }\end{array}$ & $\begin{array}{l}\text { TAACCCGAGGATCCGTGTAA } \\
\text { C }\end{array}$ & ATCTCTAGCCGCCAGCAAATC \\
\hline 265682_at & At2g24390 & $\begin{array}{l}\text { Avirulence induced gene (AIG) } \\
\text { protein, related }\end{array}$ & $\begin{array}{l}\text { CAATGCACAGTGTCTTCGTCT } \\
\text { A }\end{array}$ & $\begin{array}{l}\text { TTCGGTAAATTCAACTCTTCA } \\
\text { GC }\end{array}$ \\
\hline 254582_at & At4g19470 & Disease resistance protein, related & $\begin{array}{l}\text { CAGAAACGAAGACGGTGATT } \\
\text { AC }\end{array}$ & $\begin{array}{l}\text { TCTTCСТTTATTСТTTTССТGT } \\
\text { TC }\end{array}$ \\
\hline 267056_at & At2g32470 & F-box family protein, related & $\begin{array}{l}\text { TGGGGTTTCACAGTCAATAAT } \\
\text { AGT }\end{array}$ & TTCGCATACCAATCCCACAAC \\
\hline 248188_at & At5g54070 & Heat shock transcription factor & $\begin{array}{l}\text { TGAGTCATTGAAGGAGGAAC } \\
\text { AGAG }\end{array}$ & $\begin{array}{l}\text { GAGCCACCGTCAACAAGTAG } \\
\text { G }\end{array}$ \\
\hline 253366_at & At4g33180 & Hydrolase family protein & $\begin{array}{l}\text { TCGCAGACGCTTTCCATAGAC } \\
\mathrm{T}\end{array}$ & $\begin{array}{l}\text { GAAGAAGACAAGATCGGGAG } \\
\text { AATA }\end{array}$ \\
\hline 260699_at & Atlg32320 & MAP kinase, putative & $\begin{array}{l}\text { GACATAAAGCCTTCAAATCTC } \\
\text { C }\end{array}$ & $\begin{array}{l}\text { ATCTCCCAACAAAATCTCTAA } \\
\text { АCT }\end{array}$ \\
\hline 249440_at & At5g40030 & Protein kinase PKI- like & CTTCAAGCCTCGGTTCCTCAA & $\begin{array}{l}\text { GATCGGTTTCGGTATTTCTGG } \\
\text { TG }\end{array}$ \\
\hline \multicolumn{5}{|c|}{ B. Genes induced in PPV-infected Arabidopsis protoplasts and leaf tissues } \\
\hline 26092I_at & Atlg21540 & AMP-binding protein, putative & TTAGGGACCCGAGAACC & GCAGAGACTTAGCCATTTGT \\
\hline 258962_at & At3gl0570 & Cytochrome P450, putative & $\begin{array}{l}\text { TCGTGAGGTTGAGGAAAAAG } \\
\text { ATG }\end{array}$ & $\begin{array}{l}\text { GATAAGCGCTCCACTCAAACT } \\
\text { C }\end{array}$ \\
\hline 253502_at & At4g31940 & Cytochrome P450-like protein & TGCACGGTCGCTGGTTACT & AGGCGTGGCTTTAGGAATG \\
\hline 248989_at & At5g45200 & $\begin{array}{l}\text { Disease resistance protein, TIR-NBS- } \\
\text { LRR }\end{array}$ & ATTCTTGGTGGTTGGACTG & CACTTCTCTTTGGACTTTC \\
\hline 257229_at & At3gl6490 & Calmodulin-binding family protein & AATGAATGTGGCTGTATCC & CGTTTGCGGTTGTGGTTGT \\
\hline
\end{tabular}

aGenes shown in panels "A" and "B" were validated using semi quantitative RT-PCR.

bGenes shown in panel "B" were validated using Northern hybridizations.

cProbe set ID represents Affymeterix probe set number.

dAGI represents Arabidopsis Genome Initiative (AGI) locus identifier that corresponds to each gene represented on the array. 
Munich Information Centre for Protein Sequences: http:/ /mips.gsf.de/proj/thal/db/

\section{Authors' contributions}

$\mathrm{MB}$ carried out most of the experimental work including design of experiments, preparation and transfection of protoplasts, RNA isolation, analysis and interpretation of microarray data, and verification experiments. JSG participated in preparation and transfection of protoplasts, and isolation of RNA. T-SH prepared and inoculated Arabidopsis plants. AW conceived the work and interpreted the data. MB and AW wrote the paper. All authors have read and approved the manuscript.

\section{Additional material}

\section{Additional file 1}

Supplemental Table 1. Expression levels of genes induced in PPV-infected Arabidopsis leaf tissues 17 days post inoculation.

Click here for file

[http://www.biomedcentral.com/content/supplementary/1471-

2164-9-325-S1.pdf]

\section{Additional file 2}

Supplemental Table 2. Expression levels of genes repressed in PPVinfected Arabidopsis leaf tissues 17 days post inoculation.

Click here for file

[http://www.biomedcentral.com/content/supplementary/1471-

2164-9-325-S2.pdf]

\section{Additional file 3}

Supplemental Table 3. Expression levels of differentially regulated genes in PPV-infected Arabidopsis protoplasts.

Click here for file

[http://www.biomedcentral.com/content/supplementary/1471-

2164-9-325-S3.pdf]

\section{Additional file 4}

Supplemental Table 4. Expression levels of common genes induced in $P P V$-infected Arabidopsis protoplasts and in infected leaf tissues. Click here for file

[http://www.biomedcentral.com/content/supplementary/14712164-9-325-S4.pdf]

\section{Additional file 5}

Supplemental Table 5. Expression levels of common genes repressed in PPV-infected Arabidopsis protoplasts and in infected leaf tissues. Click here for file

[http://www.biomedcentral.com/content/supplementary/14712164-9-325-S5.pdf]

\section{Additional file 6}

Supplemental Figure 1. Hierarchical clustering of common genes that were significantly differentially regulated by PPV in infected leaf tissues and in transfected protoplast cells. Expression levels are color-coded with red indicating upregulation by pPPV-SK68; green indicating downregulation by pPPV-SK68 and black indicating no change in expression. The intensity of color represents the degree of gene expression levels. The putative function of each gene is shown on the right side of the cluster.

Click here for file

[http://www.biomedcentral.com/content/supplementary/14712164-9-325-S6.pdf]

\section{Additional file 7}

Supplemental Figure 2. K-means profiling of gene expression using 411 Arabidopsis genes differentially regulated by PPV in transfected protoplasts at three different time points. The expression profiles were grouped into twelve distinct cluster groups. The AGI locus identifier of each gene differentially regulated by PPV in the transfected protoplasts at different time points in each cluster group is shown on the right side of the cluster. Values on the $\gamma$-axis indicate the relative expression level of the gene, while the $x$-axis represents hours post transfection. Number of genes belonging to each cluster is shown in the cluster inset.

Click here for file

[http://www.biomedcentral.com/content/supplementary/14712164-9-325-S7.pdf]

\section{Additional file 8}

Supplemental Table 6. Gene expression profiles of Arabidopsis genes differentially regulated by PPV infectious clone in transfected protoplasts belonging to twelve distinct cluster groups.

Click here for file

[http://www.biomedcentral.com/content/supplementary/1471-

2164-9-325-S8.pdf]

\section{Additional file 9}

Supplemental Table 7. Identification of Prunus persica orthologs to Arabidopsis genes induced by PPV infection in the leaf tissues at 17 days post inoculation.

Click here for file

[http://www.biomedcentral.com/content/supplementary/1471-

2164-9-325-S9.pdf]

\section{Additional file 10}

Supplemental Table 8. Cross comparison of genes significantly differentially regulated by PPV ( $\geq 2.5$ - or $\leq-2.5$-fold $)$ in this study with the Arabidopsis genes regulated by other positive sense RNA viruses.

Click here for file

[http://www.biomedcentral.com/content/supplementary/14712164-9-325-S10.pdf] 


\section{Additional file 11}

Supplemental Figure 3. Confirmation of microarray data by sqRT-PCR and Northern hybridizations. Panel A shows confirmation of microarray data using sqRT-PCR for genes induced in PPV-infected Arabidopsis protoplasts. Panel B shows confirmation of microarray data using sqRTPCR (left panel) and Northern hybridizations (right panel) for Arabidopsis genes differentially regulated in PPV-infected protoplasts and in PPV-infected leaves. Probes for sqRT-PCR and Northern hybridizations were generated by PCR amplification of Arabidopsis $c D N A$ using gene specific primers shown in Table 3. sqRT-PCR of the constitutively expressed Actin 2 gene (At3g18780) was used as a loading control. pPPVSK68, a PPV infectious cDNA clone used to transfect protoplasts; pPPVSK684, a mutant non-infectious clone of pPPV-SK68 was used as a control; $h p t$, hours post transfection.

Click here for file

[http://www.biomedcentral.com/content/supplementary/14712164-9-325-S11.pdf]

\section{Acknowledgements}

We thank Drs. Laszlo Palkovics and Ervin Balazs (Agricultural Biotechnology Center, Hungary) for providing the PPV infectious clone; Drs. Hélène Sanfaçon, Brian Miki and Dan Brown (Agriculture and Agri-Food Canada) for very helpful discussion; Drs. Antonet Svircev and Lorne Stobbs (AAFC) for assistance in live virus work; and Dr. Daowen Wang (Chinese Academy of Sciences, China) and Dr. Hélène Sanfaçon for critical reading of the manuscript. This work was supported by grants to AW from AAFC and from the Natural Science and Engineering Research Council of Canada.

\section{References}

I. Maule A, Leh V, Lederer C: The dialogue between viruses and hosts in compatible interactions. Curr Opin Plant Biol 2002, 5:279-284

2. Whitham SA, Yang C, Goodin MM: Global impact: elucidating plant responses to viral infection. Mol Plant Microbe Interact 2006 , 19:1207-12।5.

3. Stange C: Plant-virus interactions during the infective process. Cien Inv Agr 2006, 33: I- I8

4. Culver JN, Padmanabhan MS: Virus-induced disease: Altering host physiology one interaction at a time. Annu Rev Phytopathol 2007, 45:22I-243.

5. Whitham SA, Wang Y: Roles for host factors in plant viral pathogenicity. Curr Opin Plant Biol 2004, 7:365-37I.

6. Wang A, Sanfaçon H, Stobbs LW, James D, Thompson D, Svircev AM, Brown DCW: Plum pox virus in Canada: progress in research and future prospects for disease control. Can J Plant Pathol 2006 28: $182-196$.

7. Golem S, Culver JN: Tobacco mosaic virus induced alterations in the gene expression profile of Arabidopsis thaliana. Mol Plant Microbe Interact 2003, 16:681-688.

8. Whitham SA, Quan S, Chang HS, Cooper B, Estes B, Zhu T, Wang X Hou YM: Diverse RNA viruses elicit the expression of common sets of genes in susceptible Arabidopsis thaliana plants. Plant / 2003, 33:27I-283.

9. Ishihara T, Sakurai N, Sekine KT, Hase S, Ikegami M, Shibata D, Takahashi $\mathrm{H}$ : Comparative analysis of expressed sequence tags in resistant and susceptible ecotypes of Arabidopsis thaliana infected with Cucumber mosaic virus. Plant Cell Physiol 2004, 45:470-480.

10. Marathe R, Guan Z, Anandalakshmi R, Zhao H, Dinesh-Kumar SP: Study of Arabidopsis thaliana resistome in response to Cucumber mosaic virus infection using whole genome microarray. Plant Mol Biol 2004, 55:50I-520.

II. Senthil G, Liu H, Puram VG, Clark A, Stromberg A, Goodin MM: Specific and common changes in Nicotiana benthamiana gene expression in response to infection by enveloped viruses. J Gen Virol 2005, 86:2615-2625.
12. Pompe-Novak M, Gruden K, Baebler Š, KrečičStres H, Kovač M, Jongsma $M$, Ravnikar M: Potato virus $Y$ induced changes in the gene expression of potato (Solanum tuberosum L.). Physiol Mol Plant Pathol 2006, 67:237-247.

13. Dardick C: Comparative expression profiling of Nicotiana benthamiana leaves systemically infected with three fruit tree viruses. Mol Plant Microbe Interact 2007, 20:1004-1017.

14. Espinoza C, Vega A, Medina C, Schlauch K, Cramer G, Arce-Johnson $P$ : Gene expression associated with compatible viral diseases in grapevine cultivars. Funct Integr Genomics 2007, 7:95-1 I0.

15. Shimizu T, Satoh K, Kikuchi S, Omura T: The Repression of Cell Wall- and Plastid-Related Genes and the Induction of Defense-Related Genes in Rice Plants Infected with Rice dwarf virus. Mol Plant Microbe Interact 2007, 20:247-254.

16. Yang C, Guo R, Jie F, Nettleton D, Peng J, Carr T, Yeakley JM, Fan JB, Whitham SA: Spatial analysis of Arabidopsis thaliana gene expression in response to Turnip mosaic virus infection. Mol Plant Microbe Interact 2007, 20(4):359-370.

17. Maule AJ, Escaler M, Aranda MA: Programmed responses to virus replication in plants. Mol Plant Pathol 2000, I:9-15.

18. Wise RP, Moscou MJ, Bogdanove AJ, Whitham SA: Transcript profiling in host-pathogen interactions. Annu Rev Phytopathol 2007, 45:329-369.

19. Carr T, Whitham SA: An emerging model system: Arabidopsis as a viral host plant. Plant Cell Monogr 2007, 2:159-183.

20. Decroocq V, Sicard O, Alamillo JM, Lansac M, Eyquard JP, Garcia JA Candresse T, Le Gall O, Revers F: Multiple resistance traits control Plum pox virus infection in Arabidopsis thaliana. Mol Plant Microbe Interact 2006, I 9(5):54I-549.

21. Benjamini $Y$, Hochberg $Y$ : Controlling the false discovery rate-a practical and powerful approach to multiple testing. JR Stat Soc Ser 1995, B57:289-300.

22. Storey JD, Tibshirani RL: Statistical significance for genomewide studies. Proc Natl Acad Sci USA 2003, 100:9440-9445.

23. Berriz GF, King OD, Bryant B, Sander C, Roth FP: Characterizing gene sets with FuncAssociate. Bioinformatics 2003, 19:2502-2504.

24. Draghici S, Khatri P, Martins RP, Ostermeier C, Krawetz SA: Global functional profiling of gene expression. Genomics 2003, 81:98-104.

25. Balachandran S, Hull RJ, Vaadia Y, Wolf S, Lucas WJ: Alteration of carbon partitioning induced by the movement protein of Tobacco mosaic virus originates in the mesophyll and is independent of change in the plasmodesmal size exclusion limit. Plant Cell Environ 1995, 18:1301-1310.

26. Técsi LI, Maule AJ, Smith AM, Leegood RC: Complex, localized changes in $\mathrm{CO} 2$ assimilation and starch content associated with the susceptible interaction between Cucumber mosaic virus and a cucurbit host. Plant $J$ 1994, 6:837-847.

27. Técsi LI, Smith AM, Maule AJ, Leegood RC: A spatial analysis of physiological changes associated with infection of cotyledons of marrow plants with Cucumber mosaic virus. Plant Physiol 1996, I I I:975-985.

28. Handford MG, Carr JP: Plant metabolism associated with resistance and susceptibility. In Natural Resistance Mechanisms of Plants to Viruses Edited by: Loebenstein G, Carr JP. Dordrecht: Springer; 2006:315-340

29. Handford MG, Carr JP: A defect in carbohydrate metabolism ameliorates symptom severity in virus infected Arabidopsis thaliana. J Gen Virol 2007, 88:337-34I.

30. Loebenstein G, Akad F: The local lesion response. In Natural Resistance Mechanisms of Plants to Viruses Edited by: Loebenstein G, Carr JP. Dordrecht: Springer; 2006:99-124.

31. Herbers K, Takahata Y, Melzer M, Mock HP, Hajirezaei M, Sonnewald $U$ : Regulation of carbohydrate partitioning during the interaction of potato virus $\mathbf{Y}$ with tobacco. Mol Plant Pathol 2000, I:5I-59.

32. Sheen J, Zhou L, Jang JC: Sugars as signaling molecules. Curr Opin Plant Biol 1999, 2:410-418.

33. Leon $P$, Sheen J: Sugar and hormone connections. Trends Plant Sci 2003, 8: I10-116.

34. Jonczyk M, Pathak KB, Sharma M, Nagy PD: Exploiting alternative subcellular location for replication: Tombusvirus replication switches to the endoplasmic reticulum in the absence of peroxisomes. Virology 2007, 362(2):320-330. 
35. Mas P, Beachy RN: Replication of Tobacco mosaic Virus on Endoplasmic Reticulum and Role of the Cytoskeleton and Virus Movement Protein in Intracellular Distribution of Viral RNA. J Cell Biol I999, I 47:945-958.

36. Sanfaçon H: Replication of positive-strand RNA viruses in plants: contact points between plant and virus components. Can J Bot 2005, 83: I529-I549.

37. Chen D, Hartweck JL, Alamillo JM, Mateo CS, Pérez JJ, FernándezFernández MR, Olszewski NE, Garcia JA: Identification of secret agent as the O-GIcNAc transferase that participates in plum pox virus infection. J Virology 2005, 79:938I-9387.

38. Hartweck LM, Scott CL, Olszewski NE: Two O-linked $\mathbf{N}$ acetylglucosamine transferase genes of Arabidopsis thaliana L. Heynh. have overlapping functions necessary for gamete and seed development. Genetics 2002, 161:1279-129|.

39. Sato S, Nakamura Y, Kaneko T, Asamizu E, Tabata S: Complete structure of the chloroplast genome of Arabidopsis thaliana. DNA Res 1999, 6(5):283-290.

40. Jin H, Li S, Villegas A Jr: Down-regulation of the 265 proteasome subunit RPN9 inhibits viral systemic transport and alters plant vascular development. Plant Physiol 2006, I42:65 I-66I.

41. Ingvardsen C, Veierskov B: Ubiquitin- and proteasome-dependent proteolysis in plants. Physiol Plant 200 I, I I 2:45I -459.

42. Reichel C, Beachy RN: Degradation of tobacco mosaic virus movement protein by the $26 \mathrm{~S}$ proteasome. J Virol 2000 , 74:3330-3337.

43. Aranda MA, Escaler M, Wang D, Maule AJ: Induction of HSP70 and polyubiquitin expression associated with plant virus replication. Proc Natl Acad Sci USA 1996, 93: I 5289- 15293.

44. Havelda Z, Maule AJ: Complex spatial responses to Cucumber mosaic virus infection in susceptible Cucurbita pepo cotyledons. Plant Cell 2000, I 2:1975-1985.

45. Kruger J, Thomas CM, Golstein C, Dixon MS, Smoker M, Tang S, Mulder $L$, Jones JD: A tomato cysteine protease required for Cf-2-dependent disease resistance and suppression of autonecrosis. Science 2002, 296:744-747.

46. Nishimura M, Somerville S: Enhanced: Resisting Attack. Science 2002, 295:2032-2033.

47. Schaller A, Ryan CA: Molecular cloning of a tomato leaf cDNA encoding an aspartic protease, a systemic wound response protein. Plant Mol Biol 1996, 3 1: 1 073-1077.

48. Padmanabhan MS, Goregaoker SP, Golem S, Shiferaw H, Culver JN: Interaction of the Tobacco mosaic virus replicase protein with the Aux/IAA protein PAPI/IAA26 is associated with disease development. J Virol 2005, 79:2549-2558.

49. Padmanabhan MS, Shiferaw H, Culver JN: The Tobacco mosaic virus replicase protein disrupts the localization and function of interacting Aux/IAA proteins. Mol Plant Microbe Interact 2006 19:864-873

50. Cecchini E, Gong Z, Geri C, Covey SN, Milner J]: Transgenic Arabidopsis lines expressing gene VI from Cauliflower mosaic virus variants exhibit a range of symptom-like phenotypes and accumulate inclusion bodies. Mol Plant Microbe Interact 1997, 10:1094-II0I.

51. Zhu S, Gao F, Cao X, Chen M, Ye G, Wei C, Li Y: The rice dwarf virus $\mathbf{P 2}$ protein interacts with ent-kaurene oxidases in vivo, leading to reduced biosynthesis of gibberellins and rice dwarf symptoms. Plant Physiol 2005, 139:1935-1945.

52. Nakao A, Yoshihama M, Kenmochi N: RPG: the ribosomal protein gene database. Nucleic Acids Res 2004, 32:D I68- 170.

53. Milioni D, Sado PE, Stacey NJ, Domingo C, Roberts K, McCann MC Differential expression of cell-wall-related genes during the formation of tracheary elements in the Zinnia mesophyll cell system. Plant Mol Biol 200I, 47:22I-238.

54. Juge N: Plant protein inhibitors of cell wall degrading enzymes. Trends Plant Sci 2006, I I:359-367.

55. Oi X, Behrens BX, West PR, Mort J: Solubilization and partial characterization of extensin fragments from cell walls of cotton suspension cultures. (Evidence for a covalent cross-link between extensin and pectin). Plant Physiol 1995, 108:|69 |- I70I.

56. Smith CM, Rodriguez-Buey M, Karlsson J, Campbell MM: The response of the poplar transcriptome to wounding and subsequent infection by a viral pathogen. New Phytologist 2004 164:123-136.

57. Takebe I: The use of protoplasts in plant virology. Ann Rev Phytopathol 1975, 13:105-125.
58. Raghupathy MB, Griffiths JS, Stobbs LW, Brown DCW, Brandle JE, Wang A: Transfection of Arabidopsis protoplasts with a Plum pox virus (PPV) infectious clone for studying early molecular events associated with PPV infection. I Virol Methods 2006 , 136:147-153.

59. Karrer EE, Lincoln JE, Hogenhout $S$, Bennett $A B$, Bostock RM, Martineau B, Lucas WJ, Gilchrist DG, Alexander D: In situ isolation of mRNA from individual plant cells: creation of cell-specific cDNA libraries. Proc Natl Acad Sci USA 1995, 92:38|4-38I8.

60. Galbraith DW, Harkins KR, Jefferson RA: Flow cytometric characterization of the chlorophyll contents and size distributions of plant protoplasts. Cytometry 1988, 9:75-83.

6I. Day RC, Grossniklaus U, Macknight RC: Be more specific! Laserassisted microdissection of plant cells. Trends in Plant Science 2005, 10:397-406.

62. Ramsay K, Jones MGK, Wang Z: Laser capture microdissection: a novel approach to microanalysis of plant-microbe interactions. Mol Plant Pathol 2006, 7:429-435.

63. Steinhart W, Renvyle TT: Cymbidium mosaic virus RNA synthesis in isolated orchid protoplasts. Virus Res 1993, 30:205-2/3.

64. Wang A, Chapman P, Chen L, Stobbs LW, Brown DCW, Brandle JE: A comparative survey, by expressed sequence tag analysis, of genes expressed in peach leaves infected with Plum pox virus (PPV) and free from PPV. Can J Plant Pathol 2005, 27:410-419.

65. Llácer G: Hosts and symptoms of plum pox virus: Herbaceous hosts. OEPP/EPPO Bulletin 2006, 36:227-228.

66. Maule AJ, Caranta C, Boulton MI: Sources of natural resistance to plant viruses: status and prospects. Mol Plant Pathol 2007, 8:223-231.

67. Meyers BC, Kozik A, Griego A, Luang H, Michelmore RW: Genomewide analysis of NBS-LRR-encoding genes in Arabidopsis. Plant Cell 2003, I 5:809-834

68. Bendahmane A, Kanyuka K, Baulcombe DC: The Rx gene from potato controls separate virus resistance and cell death responses. Plant Cell 1999, I I:78I-792.

69. Brommonschenkel SH, Frary A, Tanksley SD: The broad-spectrum tospovirus resistance gene $\mathrm{Sw}-5$ of tomato is a homolog of the root-knot nematode resistance gene Mi. Mol Plant Microbe Interact 2000, 13:1130-II38.

70. Querci M, Baulcombe DC, Goldbach RW, Salazar LF: Analysis of resistance breaking determinants of potato virus $\times(P V X)$ strain HB on different potato genotypes expressing extreme resistance to PVX. Phytopathology 1995, 85:1003-101I.

7I. Dunigan DD, Golemboski DB, Zaitlin M: Analysis of the $\mathbf{N}$ gene of Nicotiana. In Plant Resistance to Viruses Edited by: Evered D, Harnett S. Chichester, UK: Wiley; 1987:120-135.

72. Chen F, Foolad MR: Molecular organization of a gene in barley which encodes a protein similar to aspartic protease and its specific expression in nucellar cells during degeneration. Plant Mol Biol 1997, 35:82 I-83I.

73. Wang D, Maule AJ: Inhibition of host gene expression associated with plant virus replication. Science 1995, 267:229-231.

74. Lyles DS: Cytopathogenesis and inhibition of host gene expression by RNA viruses. Microbiol Mol Biol Rev 2000 , 64:709-724.

75. Rottier P: Viral protein synthesis in cowpea mosaic virus infected protoplasts. In PhD thesis University of Wageningen, The Netherlands; 1980.

76. Huang Z, Yeakley JM, Garcia EW, Holdridge JD, Fan JB, Whitham SA: Salicylic acid-dependent expression of host genes in compatible Arabidopsis-virus interactions. Plant Physiol 2005, 137:1 I47-II59.

77. Diaz-vivancos P, Rubio M, Mesonero V, Periago PM, Barcelo AR, Martínez-Gómez P, Hernández JA: The apoplastic antioxidant system in Prunus: response to long term plum pox virus infection. J Exp Botany 57:38| 3-3824.

78. Hammond-Kosack K, Jones JDG: Responses to plant pathogens. In Biochemistry and Molecular Biology of plants Edited by: Buchanan BB, Gruissem W, Jones RL. Maryland: American Society of Plant Physiology; 2000:1 I02-1I56.

79. Garcia-Brugger A, Lamotte O, Vandelle E, Bourque S, Lecourieux D, Poinssot B, Wendehenne D, Pugin A: Early signaling events induced by elicitors of plant defenses. Mol Plant Microbe Interact $2006,19: 711-724$ 
80. Taniguchi M, Miura K, Iwao H, Yamanaka S: Quantitative assessment of DNA microarrays-comparison with northern blot analyses. Genomics 2001, 71:34-39.

8I. Yao B, Rakhade SN, Li Q, Ahmed S, Krauss R, Draghici S, Loeb JA: Accuracy of cDNA microarray methods to detect small gene expression changes induced by neuregulin on breast epithelial cells. BMC Bioinformatics 2004, 5: I- 16.

82. Eisen MB, Spellman PT, Brown PO, Botstein D: Cluster analysis and display of genome-wide expression patterns. Proc Natl Acad Sci USA 1998, 95: |4863-|4868.

83. Altschul SF, Madden TL, Schäffer AA, Zhang J, Zhang Z, Miller W, Lipman DJ: Gapped BLAST and PSI-BLAST: a new generation of protein database search programs. Nucleic Acids Res 1997, 25:3389-3402.

84. Rubin GM, Yandell MD, Wortman JR, Gabor Miklos GL, Nelson CR, Hariharan IK, Fortini ME, Li PW, Apweiler R, Fleischmann W, Cherry JM, Heinkoff S, Skupski MP, Misra S, Ashburner M, Birney E, Boguski MS, Brody T, Brokstein P, Celniker SE, Chervitz SA, Coates D, Cravchik A, Gabrielian A, Galle RF, Gelbart WM, George RA, Goldstein LSB, Gong F, Guan P, Harris NL, Hay BA, Hoskins RA, Li J, Li Z, Hynes RO, Jones SJM, Kuehl PM, Lemaitre B, Littleton JT, Morrison DK, Mungall C, Farrell PHO, Pickeral OK, Shue C, Vosshall LB, Zhang J, Zhao Q, Zheng XH, Zhong F, Zhong W, Gibbs R, Venter JG, Adams $M D$, Lewis S: Comparative genomics of the eukaryotes. Science 2000, 287:2204-22I5.

Publish with Biomed Central and every scientist can read your work free of charge

"BioMed Central will be the most significant development for disseminating the results of biomedical research in our lifetime. "

Sir Paul Nurse, Cancer Research UK

Your research papers will be:

- available free of charge to the entire biomedical community

- peer reviewed and published immediately upon acceptance

- cited in PubMed and archived on PubMed Central

- yours - you keep the copyright

Submit your manuscript here:

http://www.biomedcentral.com/info/publishing_adv.asp
BiolMedcentral 